\title{
Chaquiras en el Gran Chaco: apropiaciones y negociaciones
}

\section{Glass beads in the Gran Chaco: appropriations and negotiations}

\author{
M. Alfonsina Elías ${ }^{1}$
}

\section{Resumen}

Entre distintos grupos étnicos del Gran Chaco Sudamericano, se han producido y usado, y actualmente son producidos y usados, diversos tipos de objetos tejidos y bordados con chaquiras (cuentas de vidrio), procedentes de las sociedades coloniales y nacionales. En las colecciones de museos, la mayoría de ellas formadas en la primera mitad del siglo $\mathrm{XX}$, se registran dichos objetos relacionados con el "adorno" corporal y la indumentaria, mayoritariamente atribuidos a grupos pilagá, toba-pilagá, toba oriental (qom), maká, nivaclé y lengua.

En este trabajo se intenta pensar los procesos de cambio y continuidad implicados en la producción, uso y circulación de los mismos y su participación en procesos de significación de las identidades étnicas en contextos históricos concretos. Nuestro estudio se ha concentrado en distintos aspectos de la materialidad de estos objetos (estructuras textiles, formatos, diseños y colores); el abordaje asociado de los mismos, considerando la materia prima foránea (chaquiras), permite dar cuenta de procesos de apropiación y negociación en el empleo de este tipo de cuentas, en los que los grupos étnicos se constituyen en sujetos activos en la construcción de sus culturas e identidades.

Palabras claves: cuentas de vidrio, materialidad, grupos étnicos, identidad.

\begin{abstract}
Between different ethnic groups in the South American Gran Chaco, it has been produced and used, and they are currently produced and used, various types of objects and embroidery with glass beads, from colonial and national societies. In museums collections, most of them collected during the first half of the XX century, are registered these objects related with body "ornament" and clothing, mostly attributed to Pilagá, Toba-pilagá, East Toba (Qom) Maká, Nivaclé and Lengua groups.

This paper attempts to think the processes of change and continuity involved in the production, use and circulation of them and their participation in processes of meaning of ethnic identities in specific historical contexts. Our study has focused on different aspects of the materiality of these objects (textile structures, formats, designs and colors); the associated addressing of them, considering the foreign raw material (glass beads), can account the processes of appropriation and negotiation in the use of such kinds of beads, in which ethnic groups are active participants in the construction of their cultures and identities.
\end{abstract}

Keywords: glass beads, materiality, ethnic groups, identity.

Recibido: 6 junio 2016. Aceptado: 5 diciembre 2016.

1 Área de Colecciones Etnográficas, Museo Etnográfico “J. B. Ambrosetti”, Facultad de Filosofía y Letras, Universidad de Buenos Aires, Argentina. Moreno 350 - C1091. ARGENTINA. Email: alfonelias75@gmail.com 


\section{Introducción}

El ingreso de cuentas de vidrio, abalorios, mostacillas o chaquiras ${ }^{2}$ a la región del Gran $\mathrm{Chaco}^{3}$ se produce a través del contacto con los primeros conquistadores (Escobar, 1993). El misionero jesuita Florián Paucke (1943) realiza una de las primeras referencias al uso de estas cuentas en el siglo XVIII; menciona que tanto hombres como mujeres mocoví de la misión de San Javier, en la actual provincia de Santa Fe, acostumbraban llevar en el cuello diversas sartas de cuentas de vidrio [142]. ${ }^{4}$

Recién para las primeras décadas del siglo XX se registran las siguientes referencias al empleo de chaquiras entre distintos grupos étnicos de la región. Alfred Métraux (1933) menciona que los pilagá, visitados por él en el Estero Patińo en 1933, eran excelentes

2 Chaquira es una voz quechua que, con anterioridad a la llegada de los europeos a América, específicamente al área andina, hacía referencia a sartas o collares de cuentas que no eran de vidrio, ya que esa materia prima no se conocía en el continente americano. Sin embargo, en distintos países de habla hispana como México, e incluso portuguesa (Brasil), el vocablo chaquira suele remitir a las cuentas de vidrio llegadas a América a través de los europeos. Este empleo se registra en distintos textos académicos sobre el tema, a saber: Iriarte, 2002; Lagrou, 2013; Yturbide y Mozzi, 1998, entre otros. En este artículo se emplea el término chaquira para la región del Gran Chaco en este sentido, ya que parece un uso común, como se puede constatar a partir de su definición en el Diccionario de la Real Academia Espańola: "Chaquiras: Cuentas, abalorios, etcétera, de distintas materias que llevaban los españoles para vender a los indígenas americanos".

Se usarán en el artículo indistintamente los términos chaquiras, mostacillas y abalorios, referenciando a las cuentas de vidrio traídas por los europeos a América y obtenidas por los indígenas a través de los "blancos".

3 El Gran Chaco sudamericano es una planicie de escaso relieve, limitada al oeste por las estribaciones de la cordillera de los Andes, al este por los ríos Paraguay y Paraná, al sur por el río Salado y al norte por el Matto Grosso. Abarca parte de los actuales Estados de Argentina, Paraguay y Bolivia. Es una región socio-culturalmente compleja, en la que viven distintos pueblos originarios, relacionada con otras regiones como la andina, amazónica y la pampeana (Braunstein y Miller, 1999; Wright, 2005).

4 La numeración entre corchetes corresponde a las páginas de las publicaciones referidas. en el trabajo con cuentas de vidrio, adquiriendo de ellos collares y brazaletes [204]. En su texto Ethnography of the Chaco, señala que los pilagá, ashluslay (nivaclé) y lengua hacían elaboradas bandas enhebrando cuentas de vidrio sobre un telar simple; con estas bandas se producían collares, pendientes, brazaletes, anillos y pequeñas bolsas (Métraux, 1946). José Elías Níklison (1916) habla del "malagaic", gargantilla de varios hilos de pequeñísimas cuentas de vidrio o loza, blancas, azules y rojas, como "adorno" usado por las mujeres toba (qom) [155]. Juan Vogt (1933), quien en 1927 realiza un viaje al Chaco paraguayo, señala que los maká sostenían sus cabellos con una cinta adornada de mostacillas o pedacitos de huesos y que usaban collares de mostacilla, semillas y valva [123]. Enrique Palavecino (1933), quien realiza un trabajo de campo entre distintos grupos pilagá en 1929, cuenta que las mujeres usaban pulseras con bordados de mostacillas e incluye en su artículo un dibujo de una de ellas; también hace referencia al uso de distintos tipos de collares hechos con semillas, botones de concha, dientes de animales o mostacillas de vidrio y pendientes auriculares elaborados con dichas cuentas. En su texto, Palavecino señala que las mostacillas eran adquiridas en las cantinas de los fortines militares a cambio de cueros [547-548]. Branislava Susnik (1998) propone que los chaqueńos adoptaban rápidamente cualquier materia prima del nuevo ambiente que sirviera de "ostentación sociofestival" del hombre; los abalorios eran buscados por los indígenas ya al iniciarse su primer contacto con el "ambiente blanco"; los hombres lengua, chulupíes (nivaclé), maká y toba confeccionaban anchas gargantillas y brazaletes de abalorios, así como también, bandas o vendas de lana roja en las que se cosían mostacillas [122-124].

Estas referencias permiten señalar que las chaquiras, cuentas de vidrio, abalorios o mostacillas han constituido la materia prima para la producción de diversos objetos relacionados con la indumentaria y el "adorno" corporal. En colecciones de museos, la mayoría de ellas formadas durante las primeras cuatro décadas del siglo XX, se observa el empleo destacado de chaquiras para la producción de este tipo de objetos entre los pueblos pilagá, toba-pilagá, toba oriental (qom) ${ }^{5}$ del denominado Chaco

5 En el Chaco argentino, los toba se dividen en tobas 
argentino, y maká, nivaclé y lengua del llamado Chaco paraguayo. ${ }^{6}$

Estos objetos han sido y aún son un aspecto relevante de la cultura material de algunos de estos pueblos. Sin embargo, a diferencia de otras producciones textiles, como aquellas elaboradas con caraguatá o chaguar, ${ }^{7}$ no han recibido mayor atención y análisis, probablemente por no ser considerados elementos "tradicionales", sino incorporaciones provenientes de la sociedad "blanca" que no expresan la autenticidad de estos pueblos. Cabe mencionar que, si bien no realiza un estudio detallado sobre el tema, Ticio Escobar (1993) plantea brevemente la problemática del uso de chaquiras entre los "chaqueños típicos" y propone que éste adquirió un sesgo propio, llegando a constituir una de sus manifestaciones más características. Formula que el uso de este tipo de cuentas dio posibilidad a que se desarrolle un nuevo registro ornamental sobre la base de los diseños tribales, recreando los antiguos patrones y forzándolos a cobijar colores y texturas importadas y a soltar expresiones nuevas [179-182].

Pensando la relación entre lo antiguo y lo nuevo que se deja entrever en lo esbozado por este autor,

orientales, que viven en el este de las provincias del Chaco y Formosa y tobas occidentales en el oeste de las provincias de Salta y Formosa; el grupo llamado por Alfred Métraux "toba- pilagá” vive en el oeste de Formosa (Mendoza, 1999; Wright, 2005).

6 Cabe señalar que el empleo de chaquiras se registra también entre otros pueblos del Gran Chaco, a saber: corpus museográficos chorote (manjuy), wichí e ishir. Sin embargo, no presentan la misma profusión que entre los pueblos mencionados en el texto. En los conjuntos manjuy y wichí se observan pocos casos de empleo de chaquiras para el bordado de bandas cefálicas y vinchas. En el caso ishir, del Chaco paraguayo, las chaquiras se emplean para el bordado de cinturones ceremoniales denominados pamó (Boggiani, 1900; AA.VV., 2008).

7 Caraguatá o chaguar son los nombres dados, en las zonas de influencia guaraní y quichua, respectivamente, a plantas pertenecientes a la familia de las bromeliáceas. Las fibras textiles se obtienen de las hojas. Las especies usadas con fines textiles por los indígenas de la región son: Deinacanthon urbanianum, Bromelia hieronymi y Pseudananas sagenarius. Otras especies de bromeliáceas textiles mencionadas en la bibliografía son: Bromelia serra, Bromelia balansae, Dickia ferox y Aechmea distichantha (Arenas, 1997). es interesante señalar que, en las últimas décadas, distintos estudios de las sociedades indígenas proponen pensar los procesos de cambio y continuidad en las que éstas, a lo largo de sus historias y relaciones con otras sociedades, se vieron involucradas, considerando a sus integrantes como agentes en dichos procesos y relaciones.

Guillaume Boccara (2005) habla de una "antropología diacrónica” que rechaza la perspectiva de la "pureza original" para pensar las culturas como objetos de reelaboración permanente, rebatiendo la concepción de que una sociedad, cuando adopta un elemento de otra, sufre necesariamente un proceso de aculturación impuesta, deculturación o de contaminación [10]. Señala que "[...] las culturas dominadas utilizan significantes de las sociedades dominantes para producir otros significados. De modo que resulta equivocado pretender explicar la transformación de una tradición como si se tratase de una extinción, de una decadencia o de una contaminación" [11]. Este autor cita el estudio de Michael Brown sobre los aguarana en la Amazonía ecuatoriana y peruana en tanto incluye una visión dinámica de la cultura material y la identidad de este grupo en situaciones de contacto: "En muchos de los casos su respuesta a este contacto no fue una pasiva 'aculturación' sino más bien una creativa absorción y reinterpretación de la cultura material, instituciones e ideas que llevaron a una vigorización de su propia identidad cultural" [14].

En estrecha relación con estos planteos, Janet Catherine Berlo (1996) sostiene que el "arte textil" de Latinoamérica no es una mera respuesta pasiva y defensiva a cinco siglos de colonialismo y propone considerar los procesos de apropiación implicados, posicionando a los pueblos indígenas como agentes activos de sus propios estilos artísticos y no como simples recipientes pasivos de una cultura hegemónica que constantemente erosiona y socava su cultura "tradicional" [452-453]. Sugiere considerar estos textiles como textos activos en un continuo diálogo intercultural y a sus productoras como creadoras activas de su propia cultura [459-460].

En este sentido, es interesante el estudio de Blenda Femenías (1999) sobre la indumentaria bordada y 
la identidad en el valle de Caylloma (Perú). La autora entiende la incorporación de nuevos materiales manufacturados industrialmente y producidos fuera del valle en la elaboración de la indumentaria como un proceso de apropiación por parte de los "artistas étnicos", quienes mantienen las preferencias culturales locales y las identidades étnicas en estas nuevas producciones. Plantea que la significación étnica de esta indumentaria deriva en parte de este acto de apropiación [197-198].

En estos abordajes, mediante la consideración crítica de los conceptos de aculturación (Boccara, 2005) y el acento en los procesos de apropiación (Berlo, 1996; Femenías, 1999), juega un rol central la noción de agencia de los indígenas en sus relaciones con las sociedades coloniales y nacionales, pensándolos no como sujetos pasivos frente a una cultura hegemónica y en el marco de una estructura social, sino como sujetos activos que a través de cada una de sus prácticas sociales resignifican y se apropian de aquello que proviene de dicha cultura hegemónica. Siguiendo a Sherry Ortner (2016), "[...] está en juego la importancia de cuestionar el efecto totalizador de formaciones como el colonialismo o el racismo y de tratar de observar la manera en la que los actores dominados conservan la 'agencia' [...]" [170].

Enmarcado en estas propuestas teóricas, el presente artículo plantea que la incorporación de chaquiras, procedentes de distintas instancias coloniales y nacionales, entre distintos grupos étnicos del Gran Chaco ha implicado e implica procesos de apropiación y negociación, en los que se pone en juego la agencia social de los distintos actores indígenas involucrados, participando así en la construcción de sus identidades.

Sin negar las relaciones conflictivas de dominación, consideramos que los objetos elaborados con chaquiras han constituido y constituyen espacios donde los indígenas del Chaco han pensado, recreado y dirimido las situaciones de interculturalidad y conflicto. Las prácticas de manufactura, así como las de consumo de estos objetos, involucran la puesta en juego de saberes y conocimientos locales y foráneos. En la producción, circulación y uso de dichos objetos es donde se han construido y se construyen diacrónicamente las identidades y tradiciones de estos pueblos. Es interesante señalar que el empleo de chaquiras se releva mayoritariamente en objetos de indumentaria y "adorno" corporal, los cuales participan en procesos de significación de los cuerpos que hacen a la construcción y expresión de las identidades.

En los siguientes apartados, desarrollaremos los complejos procesos de apropiación y negociación en los que se pone en práctica la agencia indígena en relación con la incorporación de chaquiras foráneas. En primera instancia, nos centraremos en los resultados del estudio de distintos aspectos de la materialidad (estructuras textiles, técnicas, formatos, diseños y colores) de los objetos elaborados con este tipo de cuentas que se encuentran en colecciones de museos; los mismos dan cuenta de dichos procesos en tanto evidencian las relaciones entre aquello que procede de las sociedades coloniales y nacionales y de las sociedades indígenas. Finalmente, se considerarán entrevistas realizadas a integrantes del pueblo maká en el año 2013, quienes hoy siguen elaborando algunos de los objetos de indumentaria y "adorno" corporal que se registran en las colecciones de las primeras cuatro décadas del siglo XX. En éstas se evidencia cómo las chaquiras y los objetos elaborados con ellas fueron y son apropiados activamente por los maká en la construcción diacrónica de su identidad en relación con otros pueblos indígenas y, especialmente, con la sociedad nacional paraguaya.

\section{Colecciones estudiadas}

Como hemos mencionado, una parte importante de nuestro estudio se basa en el relevamiento de colecciones de museos. Hemos abordado las del Museo Etnográfico "J. B. Ambrosetti” (Facultad de Filosofía y Letras, Universidad de Buenos Aires, Argentina) y las del Museo Etnográfico "Dr. Andrés Barbero" (Fundación La Piedad, Asunción, Paraguay). ${ }^{8}$

8 El relevamiento de las colecciones mencionadas implicó el estudio de la materialidad de las mismas, y también de sus historias, tanto previamente como luego de su ingreso a los museos.

El estudio de la materialidad consistió en el análisis de cada uno de los objetos, considerando la descripción de las materias primas, estructuras textiles, formatos, 
Se ha consultado, asimismo, el catálogo en línea del American Museum of Natural History (Nueva York, Estados Unidos).

La formación de estas colecciones es contemporánea a los procesos de avance de los Estados nacionales sobre los territorios indígenas en el Chaco, entre fines del siglo XIX y las primeras décadas del siglo XX. Seńalar estos contextos de recolección permite, también, dar cuenta de los contextos de circulación de los objetos estudiados aquí y de las realidades sociales de los grupos étnicos que los producían y usaban.

Las colecciones del Museo Etnográfico "J. B. Ambrosetti" con objetos elaborados con chaquiras tienen distintas procedencias y atribuciones étnicas. El total de objetos lo constituyen 153 piezas procedentes tanto del Chaco argentino como del paraguayo.

Aquellas colecciones que provienen del Chaco argentino incluyen objetos atribuidos a pueblos pilagá, toba-pilagá y toba oriental (qom). Las colecciones pilagá ingresaron de diversas formas y en distintos años al Museo Etnográfico de Buenos Aires. Las más tempranas corresponden a la donación del año 1912 por el capitán Alberto Benavidez (Catálogo de ingreso de objetos del Museo Etnográfico "J. B. Ambrosetti”, No 2, p. 193) y la del teniente Francisco María Guerrero en 1913 (Catálogo de ingreso de objetos del Museo Etnográfico “J. B. Ambrosetti”, No 3, p. 27). ${ }^{9}$

medidas, diseños y colores de los mismos, trasladando la información a fichas de análisis. Junto con la elaboración de las fichas, se llevó a cabo el registro fotográfico de cada uno de los objetos.

Al mismo tiempo, el estudio de las historias de las colecciones/objetos incluyó la consulta de material de archivo (documentos escritos y fotográficos), los catálogos de ingreso de objetos a los museos y el relevamiento de bibliografía vinculada. En las fichas mencionadas más arriba, se consignaron, entonces, otros campos relevantes para el estudio de la cultura material que integra el patrimonio de museos, a saber: forma y año de ingreso al museo, año de recolección, recolector, lugar de recolección, pueblo/nación/grupo social, procedencia geográfica, referencias bibliográficas.

9 Eduardo Saguier (s.f.) menciona, en la lista de apéndices de su obra Genealogía de la tragedia argentina. La violenta transición de un orden patrimonial-predatorio a una democracia crecientemente condicionada por el
En 1929, el etnógrafo Enrique Palavecino integra una misión del Museo de Historia Natural de Buenos Aires "Bernardino Rivadavia" y visita distintos grupos Pilagá que se encontraban entre las localidades de Paagañí y Kaalasé sobre el río Pilcomayo (Palavecino, 1933); entre ellos recolecta distintos objetos que ingresan al Museo "Bernardino Rivadavia” (Catálogo de ingreso de objetos del Museo de Historia Natural de Buenos Aires "Bernardino Rivadavia”, 1929-1945, pp. 1-20). ${ }^{10}$

En 1939, el etnógrafo suizo Alfred Métraux realiza una donación al Museo Etnográfico de Buenos Aires; en la misma se registran objetos realizados con chaquiras procedentes de Sombrero Negro, atribuidos a grupos pilagá y toba-pilagá (Catálogo de ingreso de objetos del Museo Etnográfico "J. B. Ambrosetti”, $\mathrm{N}^{\circ}$ 6, pp. 176-178). ${ }^{11}$

pretorianismo (1870-1912), la existencia, en el Archivo General del Ejército Argentino, de un documento incluyendo el diario de marcha, del 4 de noviembre del 1912, del capitán Alberto Benavides (jefe de Patrulla) al jefe del C-7 en Presidencia Roca (AGE, Leg. 1040, fs. 26-30) (p. 19). Podemos concluir que el capitán Alberto Benavides mencionado en el catálogo del museo es la misma persona mencionada en estos archivos. Cabe aclarar que el C-7 de dicho documento es el Regimiento de Caballería No 7 que actuaba en el Chaco. Desde 1911 la División de Caballería del Chaco estaba a cargo del coronel Enrique Rostagno. Ésta era conformada por los regimientos 5, 6, 7 y 9 de Caballería. Para la época de la donación, los distintos regimientos habían procedido al adelantamiento de las fronteras. El Regimiento de Caballería No 7, en 1911, se asentó en Presidencia Roca y ocupó los fortines Uriburu, Beltrán y Brown (Beck, 1994)

Para 1913, el teniente Francisco María Guerrero actuaba en el Regimiento No 9 de Caballería de Línea y envía los objetos desde Comandante Fontana (Formosa) (Guerrero, F. a J. B. Ambrosetti, 2 de octubre, 1913). El Regimiento No 9, para la misma fecha, había avanzado hasta el km 521 de la línea Embarcación- Formosa (después Comandante Fontana) y había adelantado fortines a Pegadla, Capilé, Yunká y Lagadik (Beck, 1994).

10 Cabe aclarar que, en el año 1947, las colecciones etnográficas y arqueológicas del Museo de Ciencias Naturales "Bernardino Rivadavia" fueron donadas, por decreto, al Museo Etnográfico "J. B. Ambrosetti” y es por ello que actualmente integran el patrimonio de este último.

11 Entre sus viajes de estudio al Chaco, Alfred Métraux realiza una expedición al Chaco central en el año 1939 por medio de una beca de la John Simon Guggenhein 
Los objetos toba oriental (qom) son recolectados en la excursión que realiza Enrique Palavecino en el año 1935 para el Museo de Historia Natural "Bernardi no Rivadavia” (Palavecino, 1935); éstos son atribuidos a la "Tribu de Lañagashik y Takshik" (Catálogo de ingreso de objetos del Museo de Historia Natural de Buenos Aires "Bernardino Rivadavia", 1929 1945, pp. 90-97). Otro corpus de objetos toba oriental son recolectados por la Dra. Wanda Hanke en la Reducción Bartolomé de las Casas (Formosa), en el año $1938 .{ }^{12}$

Las colecciones provenientes del Chaco paraguayo con objetos de mostacillas son atribuidas a grupos maká, nivaclé y lengua. Las colecciones maká se conforman por la recolección de la Dra. Wanda Hanke en su viaje del año 1938 y provienen de las "regiones del Río Negro y Estero Patiño, alrededores del Fortín General Aquino" (Catálogo de ingreso de objetos del Museo de Historia Natural de Buenos Aires "Bernardino Rivadavia”, 1929-1945, pp. 142-144). Además, en el año 1939, el Museo de Ciencias Naturales "Bernardino Rivadavia” compra objetos a indígenas maká que estaban en La Rural (Buenos Aires) presentando el 'espectáculo' "Aldea India" (Catálogo de ingreso de objetos del Museo de Historia Natural de Buenos Aires "Bernardino Rivadavia”, 1929-1945, pp. 156-164). ${ }^{13}$

Memorial Foundation, visitando y alojándose en misiones anglicanas de la región, entre ellas Sombrero Negro (Bilbao, 2002).

Durante este viaje forma colecciones que se encuentran en el American Museum of Natural History, que se pueden consultar actualmente en su catálogo en línea; en ellas se registran objetos elaborados con chaquiras, atribuidos mayoritariamente a grupos pilagá de Laguna de los Pájaros, toba de Sombrero Negro y “chulupí” (nivaclé) del río Pilcomayo (https://anthro.amnh.org ).

12 Los objetos recolectados por la Dra. Wanda Hanke en su viaje de estudio de 1938, son comprados por el Museo de Ciencias Naturales "Bernardino Rivadavia" (Catálogo de ingreso de objetos del Museo de Historia Natural de Buenos Aires "Bernardino Rivadavia", 1929-1945, p. 136).

13 En el año 1939, es traído a Buenos Aires, por la intermediación del general Juan Belaieff, el 'espectáculo' “Aldea india” integrado por hombres y mujeres maká, el cual se realiza en La Rural. Allí asisten distintos etnógrafos de la época, entre ellos Alfred Métraux y Enrique Palavecino (Giordano, 2004).
Las colecciones nivaclé se conforman por la compra por parte del Museo "Bernardino Rivadavia" a la Dra. Wanda Hanke en 1938; éstas provienen del Estero Patiño (Catálogo de ingreso de objetos del Museo de Historia Natural de Buenos Aires "Bernardino Rivadavia”, 1929-1945, pp. 145-147). Asimismo, Enrique Palavecino realiza una excursión en 1943, en la que recolecta objetos en la Misión Esteros (Paraguay), ingresando éstos al Museo "Bernardino Rivadavia" (Catálogo de ingreso de objetos del Museo de Historia Natural de Buenos Aires "Bernardino Rivadavia", 1929-1945, p. 240). Finalmente, Osvaldo Paulotti y Adolfo Dembo realizan una expedición, en 1940, recolectando objetos en Laguna Escalante, López de Filippis y Puesto Moreno (Paraguay) (Catálogo de ingreso de objetos del Museo Etnográfico “J. B. Ambrosetti, No 6, pp. 183-189).

Las colecciones lengua se forman por la recolección de Wanda Hanke en 1938, en el "Río Confuso, tres leguas del punto San José (Estancia Galileo)" (Catálogo de ingreso de objetos del Museo de Historia Natural de Buenos Aires "Bernardino Rivadavia", 1929-1945, pp. 140-141), y por la donación del Sr. Horacio Harrington al museo, en 1932, proveniente de "Monte Sociedad (Paraguay), cercanías de Villa Hayes" (Catálogo de ingreso de objetos del Museo Etnográfico "J. B. Ambrosetti, No 6, pp. 129).

Las colecciones del Museo Etnográfico "Dr. Andrés Barbero", con un total de 44 objetos atribuidos a grupos maká, lengua y nivaclé del Chaco paraguayo, se conforman casi contemporáneamente a la Guerra del Chaco entre Paraguay y Bolivia (1932- 1935), entre los ańos 1931 y 1937, con recolecciones de Max Schmidt, Andrés Barbero, el general Juan Belaieff, entre otros, y la donación de los oblatos de María Inmaculada en la Misión Esteros (Paraguay) (Elías y Mencia, 2012).

\section{Saberes técnicos y formatos: la producción como espacio de apropiación y negociación}

En su texto Ethnography of the Chaco, Alfred Métraux (1946) atribuye a los misioneros la introducción de las cuentas de vidrio y la enseñanza del trabajo con las mismas entre los indígenas del Chaco [275]. 


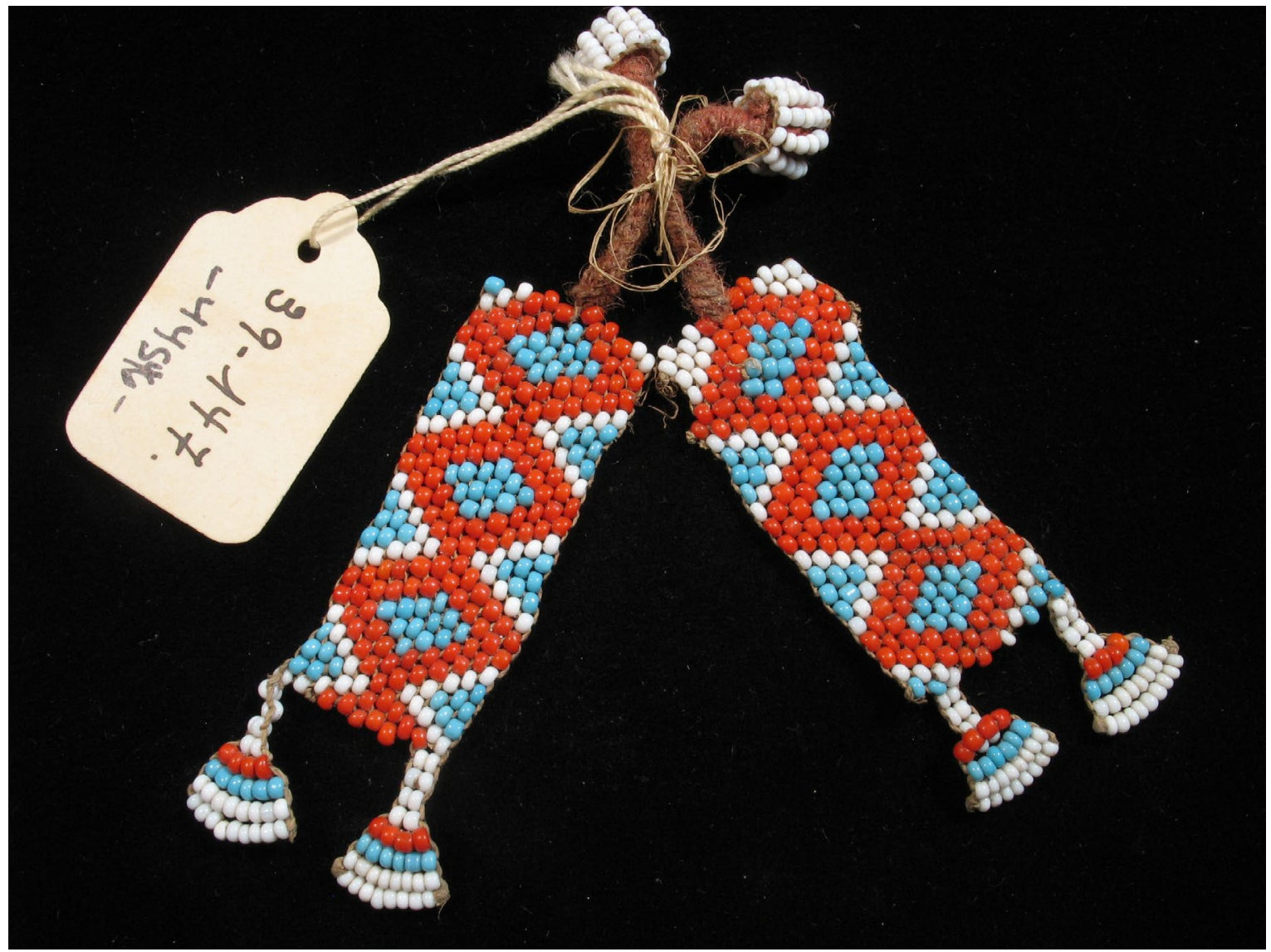

Figura 1. Pendientes auriculares en tejido "tipo red” compacto, Maká, 1939. Colección del Museo Etnográfico "J. B. Ambrosetti”.

Las instancias de producción de objetos constituyen espacios de significación y construcción de identidades y tradiciones. Aun siendo importadas las técnicas y los materiales, las mujeres indígenas del Gran Chaco se apropiaron de ellos, al tiempo que crearon nuevas técnicas a través de las cuales produjeron objetos nuevos y objetos ya conocidos que han incidido en los procesos sociales de sus pueblos. En sus prácticas de producción, las mujeres de los diferentes grupos étnicos del Gran Chaco abordaron las chaquiras foráneas poniendo en juego saberes, concepciones y conocimientos locales.

El análisis y la puesta en relación de distintos aspectos de la materialidad de los objetos producidos con abalorios, que se encuentran en distintas colecciones de museos, permiten dar cuenta de dichos procesos de negociación y apropiación en los que se puso en juego la agencia de las productoras, por lo menos para las primeras cuatro décadas del siglo XX. Nos referimos específicamente a las estructuras textiles $\mathrm{y}$ a los formatos de los objetos.

Las estructuras textiles ${ }^{14}$ que se han registrado en los objetos de las colecciones estudiadas son:

- Sartas simples: cuentas de vidrio ensartadas en un hilo de caraguatá.

- Tejidos "de" cuentas, donde éstas ofician de enlace y constituyen elementos estructurales:

a. Tejidos "tipo red", realizados con un hilo de caraguatá: a) compactos (1 cuenta saltada, 1 cuenta agregada, 1 cuenta ensartada) (Figura 1); b) reticulados (3 o 5 cuentas

14 Las categorías de estructuras textiles con cuentas se basan principalmente en las definiciones de Suárez (2010) y Seiler-Baldinger (1994). 


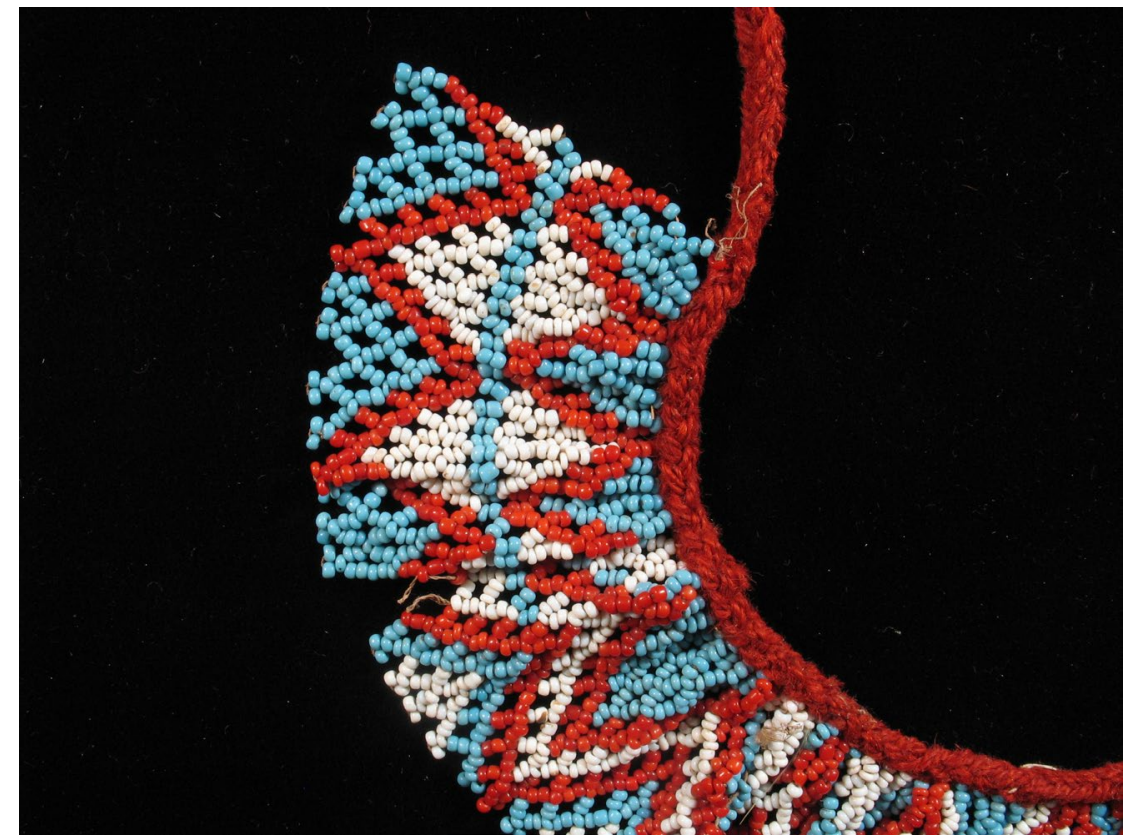

Figura 2. Detalle de gargantilla en tejido "tipo red” 5/5, Lengua, 1938. Colección del Museo Etnográfico “J. B. Ambrosetti”.

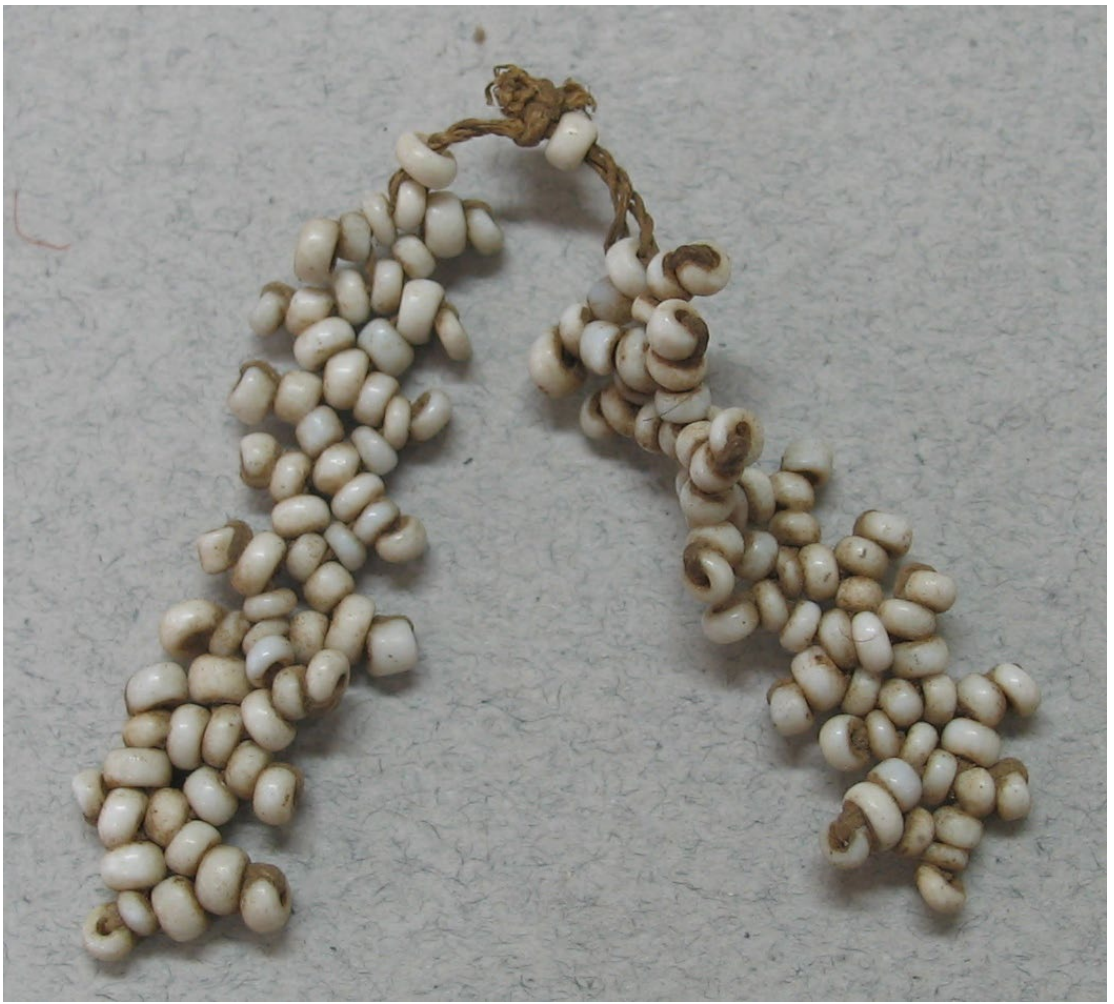

Figura 3. Pendientes auriculares en tejido "tipo trenzado" con una cuenta de enlace, Nivaclé, Esteros, 1935- Colección del Museo Etnográfico “Dr. Andrés Barbero”. 
saltadas, 3 o 5 cuentas agregadas, 1 cuenta ensartada) (Figura 2);

b. Tejidos "tipo trenzado", realizados con un conjunto de hilos de caraguatá, con enlace directo y enfrentado: a) 3 o 5 cuentas agregadas, 1 cuenta de enlace (formando una retícula romboidal) (Figura 3); b) varias cuentas agregadas, 2 o más cuentas de enlace; c) sin cuentas de relleno, 2 o más cuentas de enlace.

- Bordados:

a. Con sartas: sobre un hilo de caraguatá se ensartan las cuentas, cada determinada cantidad de cuentas se realiza una puntada en el tejido base: a) una o varias sartas paralelas avanzando en una misma dirección, los diseños se forman por la orientación de la sarta (recta o diagonal) y por el cambio de color de las cuentas; b) una sarta que, luego de cada puntada de fijación, toma la dirección opuesta.

b. Formando un tejido reticular de un conjunto de elementos ( 3 o 5 cuentas ensartadas y una cuenta de enlace) al mismo tiempo que se realiza el bordado (Elías, 2011; Elías, 2012).

En los dos apartados siguientes, nos centraremos, primero, en los objetos elaborados con sartas y tejidos "de" chaquiras para luego abordar los bordados con cuentas de vidrio.

\section{Sartas y tejidos "de" chaquiras}

Las sartas se registran en collares elaborados con semillas y dientes, por lo tanto no era una técnica desconocida por las mujeres. Según algunos autores, los collares o bandoleras de semillas eran usados mayormente por las mujeres (Nordenskiöld, 1929; Susnik, 1998). En las diferentes colecciones analizadas y también en fotografías, se registran collares conformados por largas sartas de mostacillas, relevándose casos en los que se emplearon cuentas de vidrio rojas o cuentas rojas, azules y blancas combinadas, y, en varios ejemplos, solo chaquiras blancas (Figura 4).

En cuanto al empleo de sartas de chaquira blancas, es interesante hacer referencia a lo mencionado por Félix Zorrilla, un anciano maká entrevistado en el año 2013, quien señala que antes de "conseguir" las mostacillas se usaba "collar [...] de caracol". ${ }^{15}$ Distintos autores mencionan la confección y el uso de estos collares de valva blanca por parte de los indígenas del Chaco (Figura 5). Se llevaban en varias vueltas alrededor del cuello o cruzados en bandolera (Braunstein, 1982; Escobar, 1993; Mendoza, 1983; Nordenskiöld, 1929; Palavecino, 1933). Susnik (1998) -para los lengua y nivaclé-y Métraux (1946) refieren que estos collares eran usados por los hombres y señalan su papel destacado en el intercambio entre los grupos étnicos y como demostración de 'riqueza' [116; 277]. Marcela Mendoza informa, a partir del trabajo de campo con Pascual Buija (qom del este de Formosa), que en los bailes la mujer usaba los collares realizados con la valva de río en forma de bandolera (Mendoza, 1983).

Ticio Escobar ha propuesto que los collares manufacturados con sartas de mostacillas podrían constituir una parcial sustitución de las conchillas (Escobar, 1993). En el presente trabajo, nos interesa plantear que la inclusión de chaquiras blancas (obtenidas del intercambio con distintos actores "blancos") en la producción y uso de los collares en sartas se dio a través de saberes y conocimientos locales, específicamente aquellos vinculados con la producción tradicional de los collares en sartas de semillas, etcétera, y de los collares de valvas blancas.

Estos últimos eran elaborados por medio del enlazado en forma de anillo de un hilo de caraguatá, mientras que la manera de producir los collares de chaquiras, según lo relevado en las colecciones estudiadas, era diferente en tanto éstas se ensartaban, aunque también sobre hilo de caraguatá. En los collares elaborados enteramente con sartas de chaquiras blancas, se observa la apropiación selectiva del nuevo material, combinado con un material ya conocido (el caraguatá), y la implementación de una técnica diferente a la de la producción de los collares de cuentas de valva blanca. Ahora bien, como se deduce de lo previamente mencionado, la técnica de ensartado era conocida, ya que se usaba para elaborar los collares de semillas, dientes, etcétera. Además, los collares de chaquiras blancas ensartadas se

15 Elías, M. A. (2013, 23 de octubre). Entrevista a Félix Zorrilla, traducción de Emilio Torres, Nueva Colonia Indígena Maká, Mariano Roque Alonso, Paraguay. 


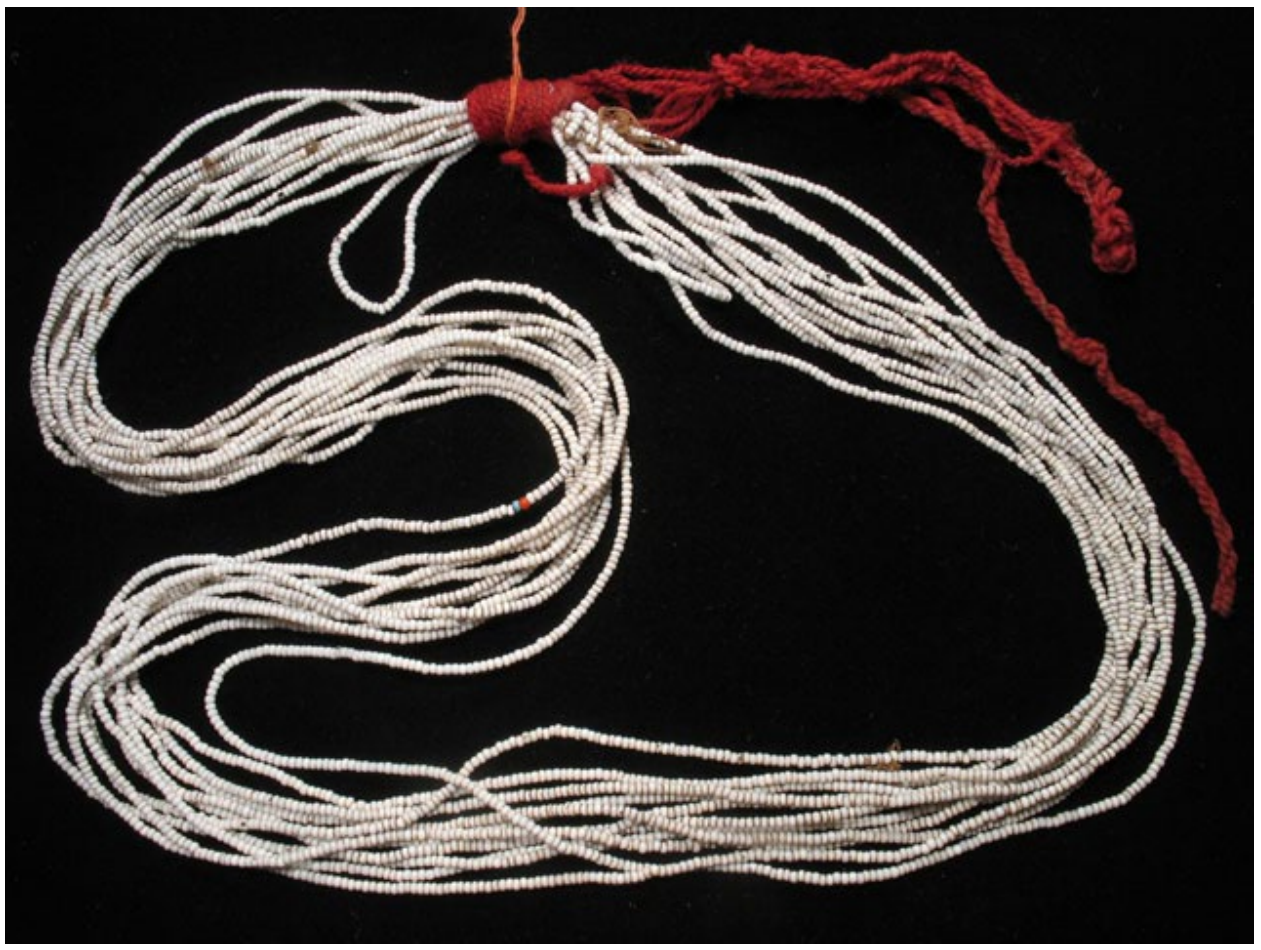

Figura 4. Collar en sarta de chaquiras blancas, Nivaclé, 1943. Colección del Museo Etnográfico "J. B. Ambrosetti”.

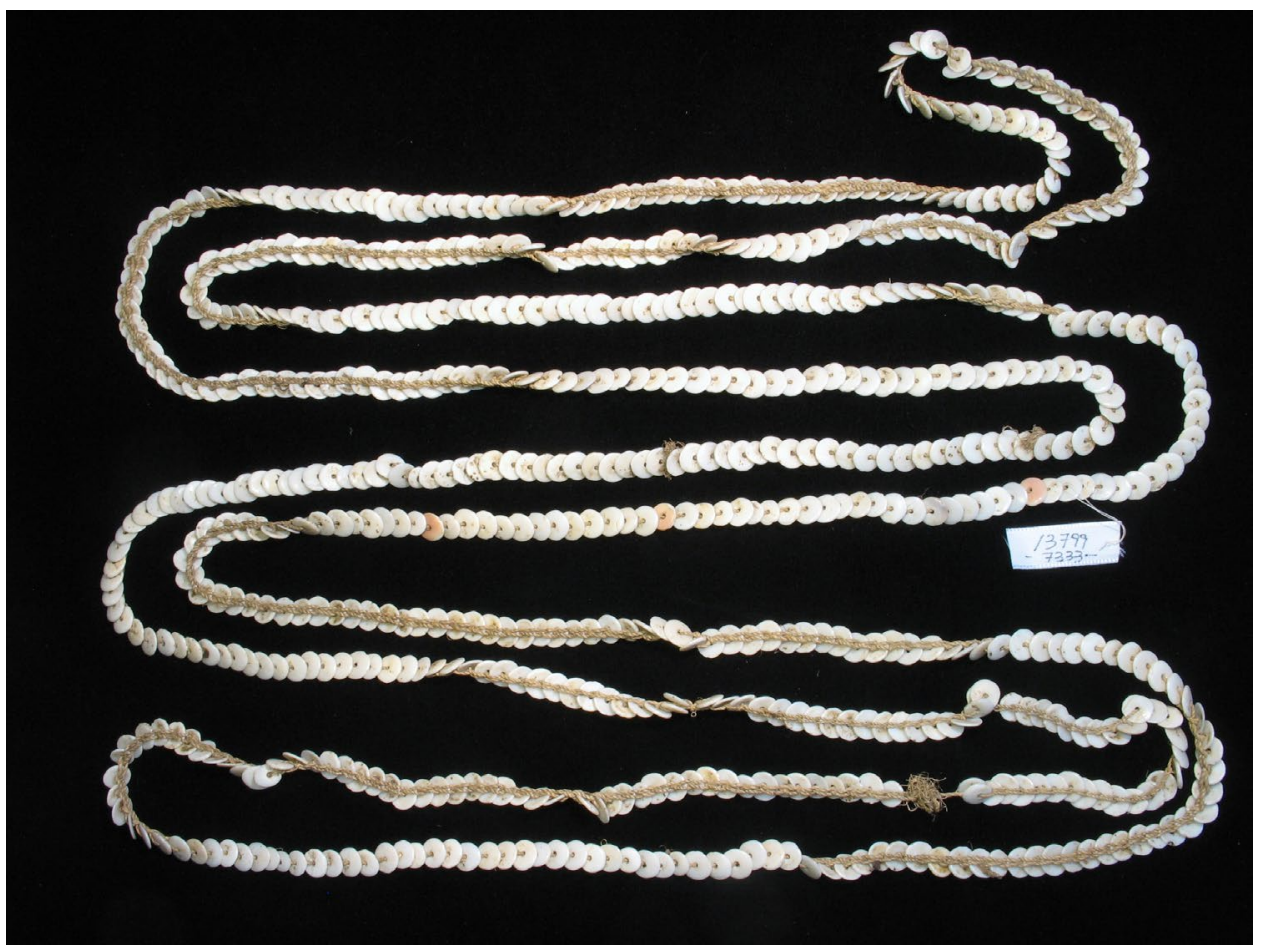

Figura 5. Collar de cuentas de valva unidas por enlace anillado de hilo de caraguatá, Pilagá, 1913. Colección del Museo Etnográfico “J. B. Ambrosetti”. 


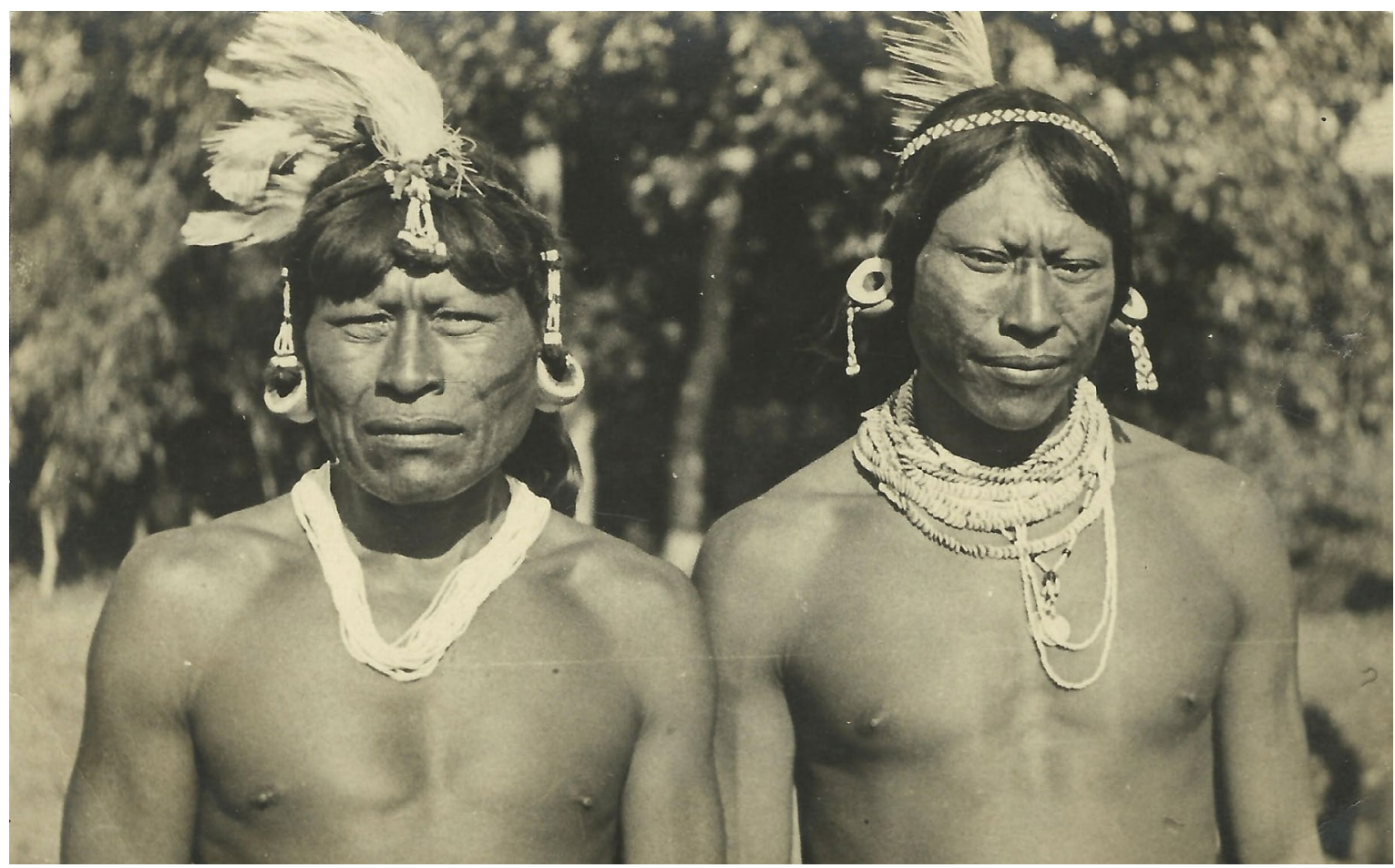

Figura 6. Hombres Maká llevando alrededor del cuello un collar en sarta de chaquiras blancas (izq.) y un collar de cuentas de valva blanca (der.), Jardín Botánico, Asunción, 1935. Colección del Museo Etnográfico "Dr. Andrés Barbero".

relacionan con un formato y el uso de un "adorno" corporal local: los largos collares de cuentas de valvas blancas que daban vueltas alrededor del cuello o se usaban en bandolera. Esto queda evidenciado en la fotografía de dos hombres maká de la década del treinta del siglo XX (Figura 6), en la que se puede observar que uno de ellos lleva un collar de cuentas circulares de valvas blancas y el otro un collar de chaquiras blancas, ambos usándolos de la misma manera, alrededor del cuello y dando varias vueltas.

En cuanto a los objetos realizados con distintos tipos de tejidos "de" cuentas de vidrio, es interesante constatar que en la mayoría de los casos, a excepción de pequeñas bolsas, sus formatos no se registran elaborados con otros tipos de cuentas o materiales. Esto permitiría hipotetizar que los mismos constituyeron novedades dentro de la cultura material indígena y que implicaban una especificidad en cuanto a los saberes y conocimientos que conllevaba su producción. ${ }^{16}$

16 Consideramos que es a este tipo de objetos, y más específicamente los elaborados en tejido "tipo red", a los que se refiere Métraux (1946) al hablar de "bandas anchas" [275].
En tejido de chaquiras "tipo red" compacto $(1 / 1)^{17}$ hay pendientes pectorales (Figura 7), anillos y brazaletes en colecciones lengua, pilagá, toba-pilagá, toba oriental (qom), maká y nivaclé. También, pendientes auriculares rectangulares en los corpus maká (Figura 1) y pequeñas bolsas toba-pilagá, pilagá y nivaclé. Los pendientes pectorales y los brazaletes presentan un formato rectangular en todos los casos estudiados. Los pendientes pectorales suelen estar cosidos, por uno de sus lados más cortos, a un cordón de lana roja trenzado o bien a una sarta de chaquiras (ver Figura 7). Los brazaletes presentan, sobre cada uno de sus lados más cortos, una trenza de lana roja que sirve para sujeción.

El tejido de chaquiras "tipo red" reticulado $(3 / 3$, $5 / 5)^{18}$ se observa en anchas gargantillas (Figura 8) en colecciones lengua, pilagá, nivaclé y maká, y en

17 La relación $1 / 1$ se refiere a la cantidad de cuentas saltadas y ensartadas. En este caso, corresponde a una cuenta saltada y una cuenta ensartada.

18 La relación $3 / 3$ y 5/5 se refiere a las cuentas saltadas y ensartadas, entre ellas una tiene la función de cuenta de enlace. 


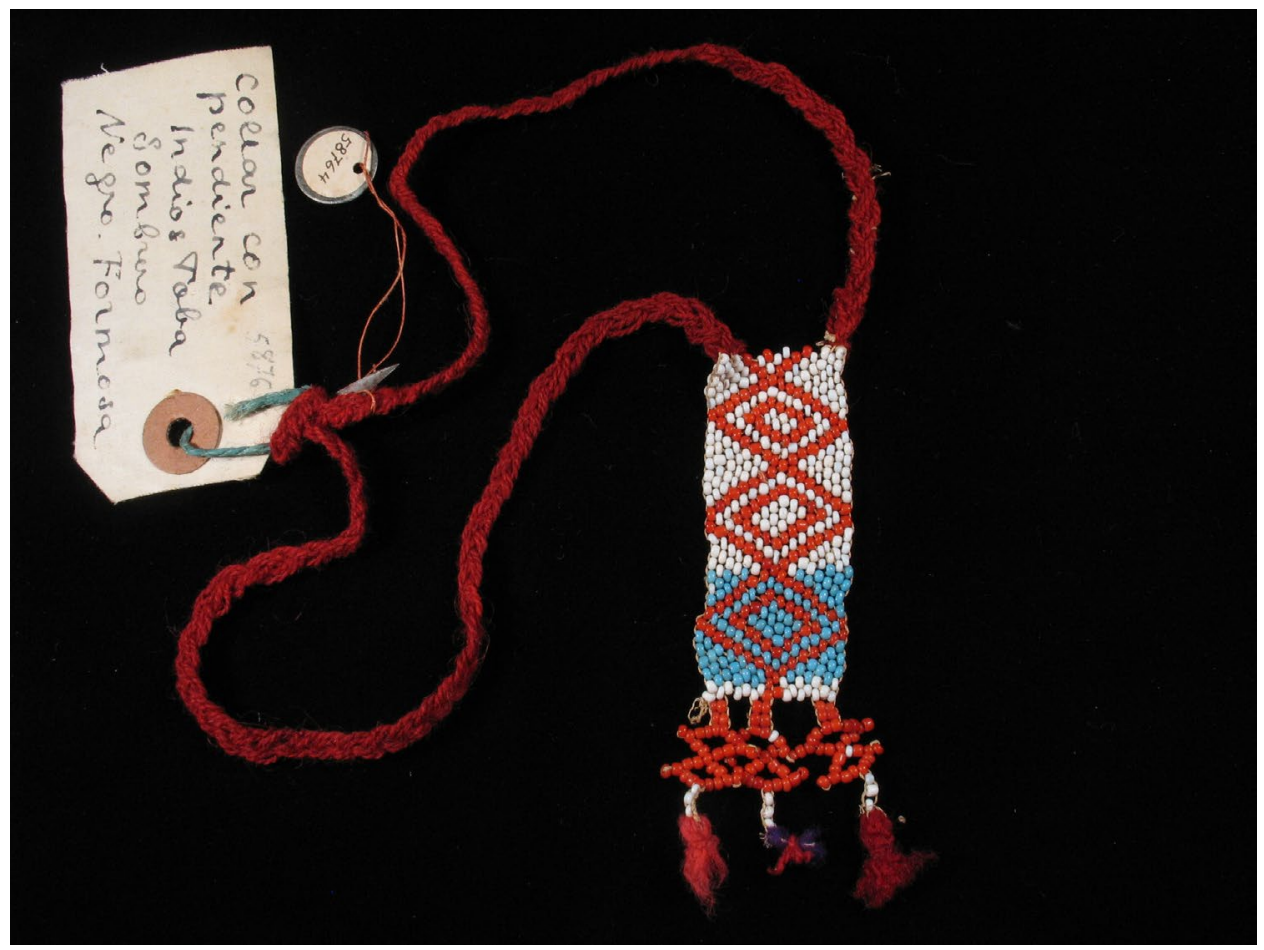

Figura 7. Pectoral en tejido “tipo red” compacto, Toba-pilagá, Sombrero Negro, 1939. Colección del Museo Etnográfico “J. B. Ambrosetti”.

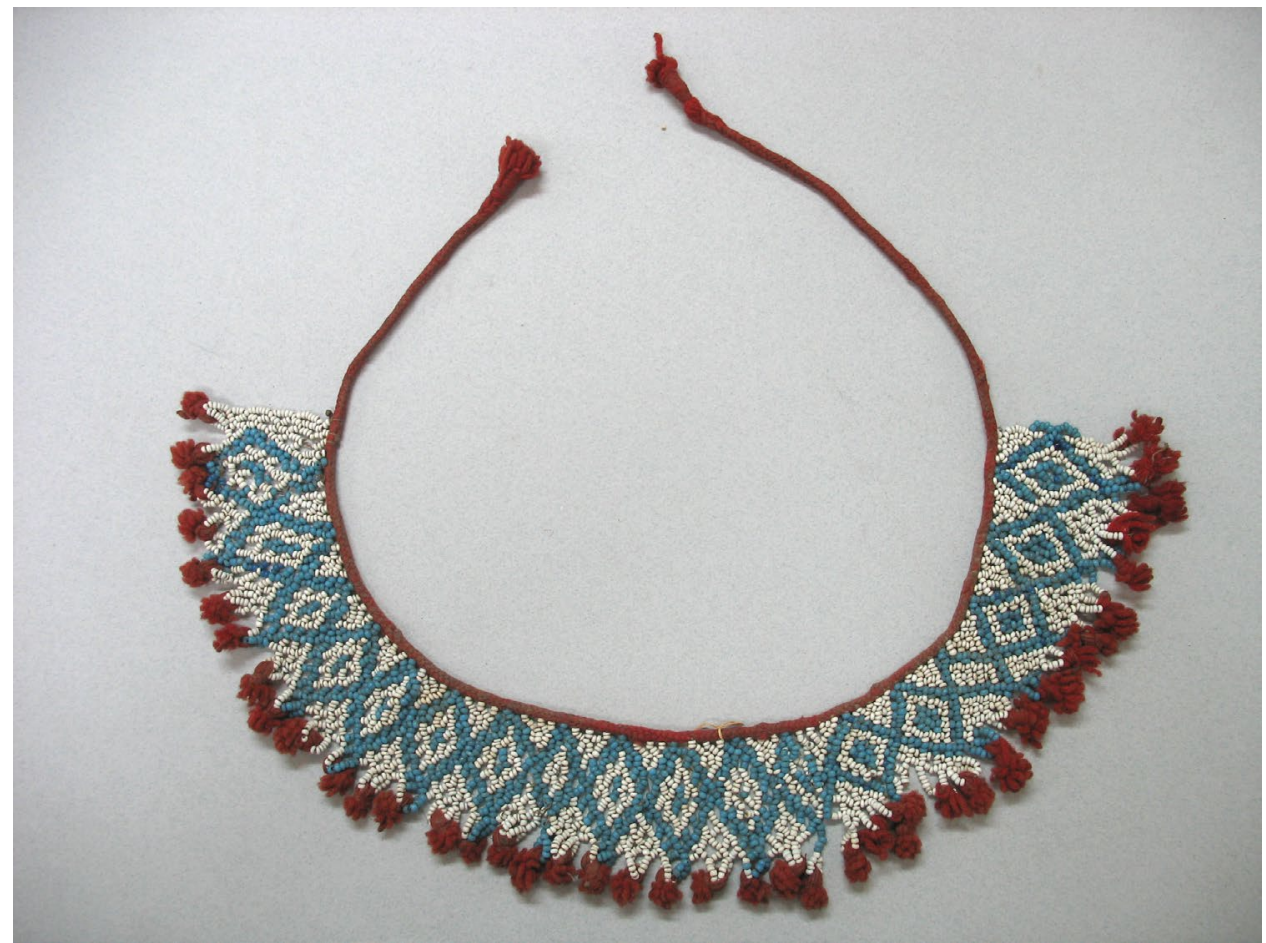

Figura 8. Gargantilla en tejido "tipo red” reticular, Lengua, 1934. Colección del Museo Etnográfico "Dr. Andrés Barbero". 


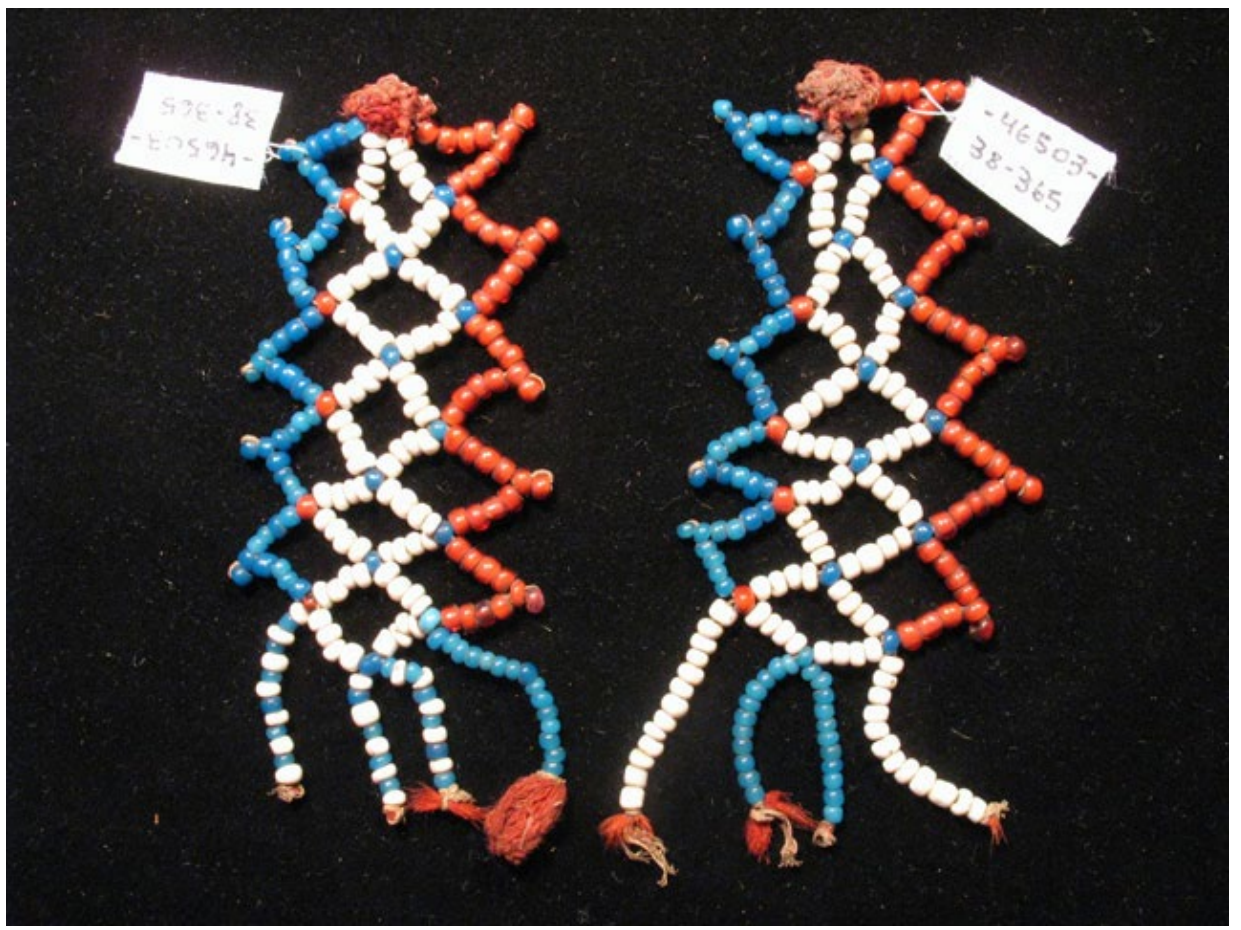

Figura 9. Pendientes en tejido "tipo trenzado" con una cuenta de enlace, Lengua, 1938. Colección del Museo Etnográfico "J. B. Ambrosetti”.

pequeñas bolsas atribuidas a grupos pilagá y tobapilagá. Al igual que lo señalado para los pectorales y los brazaletes, el tejido de chaquiras de las gargantillas tiene forma rectangular y está sujeto, en la mayoría de los casos, a una trenza de lana roja que termina en borlas; el tejido es elaborado directamente sobre la trenza.

Estas terminaciones y formatos que señalamos presentan uniformidad en los corpus atribuidos a distintos grupos étnicos, lo que permite sugerir que los objetos que los presentan han tenido relevancia y estuvieron asociados a una profusa circulación entre dichos grupos, así como las materias primas, saberes y prácticas de producción vinculados a ellos.

El tejido "tipo trenzado" se registra en distintas formas de pendientes, pectorales (Figura 9), pendientes auriculares (Figura 3) y collares en corpus pilagá, maká, toba-pilagá, nivaclé y lengua. Los formatos de los objetos elaborados de esta forma presentan mayor variabilidad que los tejidos "tipo red". Sin embargo, las estructuras textiles relacionadas con el tejido de chaquiras "tipo trenzado" son comunes en conjuntos atribuidos a los diferentes grupos étnicos, lo cual permite hipotetizar que, también, han tenido gran circulación entre ellos.

Por lo tanto, se puede plantear que la incorporación y/o creación de estas nuevas técnicas vinculadas con las chaquiras (tejido "tipo red" y tejido "tipo trenzado") involucraron la creación de nuevos formatos de objetos y que éstos devinieron relevantes en el conjunto de la cultura material relacionada con el "adorno" corporal. La importancia de estos objetos queda expresada en los textos de distintos autores que no pueden dejar de mencionarlos como parte de la indumentaria y los "adornos" corporales de estos grupos (Chase-Sardi, 2003; Escobar, 1993; Gómez-Perasso, 1977; Métraux, 1946; Palavecino, 1933; Susnik, 1998).

Sumado a esto, como veremos en el apartado "Diseños y colores: nuevos soportes para imágenes conocidas", la creación-incorporación de estos nuevos objetos se tradujo en la generación de nuevos espacios donde resignificar las identidades y símbolos grupales en los cuerpos. 


\section{Bordados de chaquiras}

El bordado de cuentas de vidrio se registra en distintos objetos que integran la indumentaria y accesorios de indumentaria de los diferentes pueblos, como bandas cefálicas, cintas para atar el cabello, vinchas, cinturones y fajas. En éstos, también se observa la aplicación de las cuentas circulares de valva elaboradas por los indígenas, que hemos mencionado más arriba para la manufactura de collares.

Los bordados con abalorios presentan estructuras textiles diferentes a las de aquellos bordados con cuentas de valva, lo cual puede ser considerado un indicio de la incorporación/creación de nuevos conocimientos técnicos. El bordado de las cuentas de valva se realiza aplicando una cuenta por vez: se ingresa el hilo de caraguatá a través del orificio central de la cuenta, para luego realizar una puntada en el soporte textil y salir por el mismo orificio, repitiendo el procedimiento con la cuenta contigua. En la mayor cantidad de los casos analizados con bordado de chaquiras no se aplica una cuenta por vez, sino que se cargan sartas $y$, cada determinada cantidad de cuentas, se realiza una puntada en el tejido base.

A continuación desarrollaremos brevemente los objetos en los que se registran bordados de cuentas y haremos referencia a sus usos y circulación.

El empleo de bandas cefálicas o frontales de lana roja con arreglos de plumas y bordados de cuentas es mencionado por diferentes autores para distintos grupos étnicos del Gran Chaco (Figuras 10 y 11). Métraux (1946) señala que éstas son tocados distintivos de los hombres de los grupos del sur del Chaco (wichí, toba, pilagá, lengua, nivaclé) [275]. Millán de Palavecino (1973) menciona que eran usadas por los shamanes o los guerreros [80-81]. Entre los maká, éstas constituyen un tocado de baile del hombre adulto (Braunstein, 1982). Las bandas cefálicas o frontales de lana, así como las vinchas más angostas, presentan las mismas estructuras textiles entre los diferentes grupos étnicos: tejido llano/faz de urdimbre con terminaciones estructurales en ambos extremos, trenzadas o bien en tejido llano/faz de urdimbre. Ticio Escobar $(1993,2007)$ señala que las plumas que acompañan estos tocados constitu- yen un verdadero lenguaje social y simbólico, respondiendo a codificadas pautas respecto a su uso y color. El guerrero que conseguía arrancar la cabellera del enemigo tenía derecho al penacho de plumas rojas o a los aderezos de picos de distintas aves; un cazador hábil podía aspirar a utilizar "copetes artísticos" (plumas recortadas) o el penacho de plumas de garza blanca; al shamán le correspondían las plumas rojas del pato real $\mathrm{u}$ otras aves igualmente poderosas $[146,100]$.

Las cintas y cordones de lana roja para atar el cabello eran empleadas mayoritariamente por los hombres; además, con ellas se ataban los collares de distintas cuentas (Gómez-Perasso, 1977; Mendoza, 1981). Estos usos actualmente se observan entre los maká. Las cintas y cordones se caracterizaban por presentar flecos con borlas en sus extremos, donde se concentra el bordado de cuentas. La presencia de borlas de lana roja con bordados de cuentas en distintos objetos como bolsas, collares, brazaletes, cinturones y fajas ceremoniales, pendientes pectorales y pendientes auriculares es señalada por distintos autores (Escobar, 1993; Gómez-Perasso, 1977; Mendoza, 1983; Métraux, 1946).

Los cinturones de lana roja con bordados de cuentas se registran en corpus atribuidos a grupos lengua, pilagá, maká y qom oriental. Consisten en una banda de lana roja en tejido llano/faz de urdimbre con flecos sobre uno de sus lados más largos. Entre los maká son usados por los hombres en contextos ceremoniales y festivales junto con los faldellines de plumas de ñandú (AA.VV., 2008; Gómez-Perasso, 1977).

Las fajas con bordados de chaquiras y/o cuentas de valva, especialmente en los flecos de los extremos y en las borlas, se registran en colecciones maká y nivaclé. Están elaboradas en tejido llano/faz de urdimbre con lana roja y presentan flecos estructurales en ambos extremos. Escobar (1993) hace referencia a su uso ceremonial [73].

A partir de las descripciones anteriores, se puede señalar que las chaquiras parecen haber sido sustitutos de las cuentas de valva blanca; es decir, que su incorporación y empleo en los bordados de ciertos 


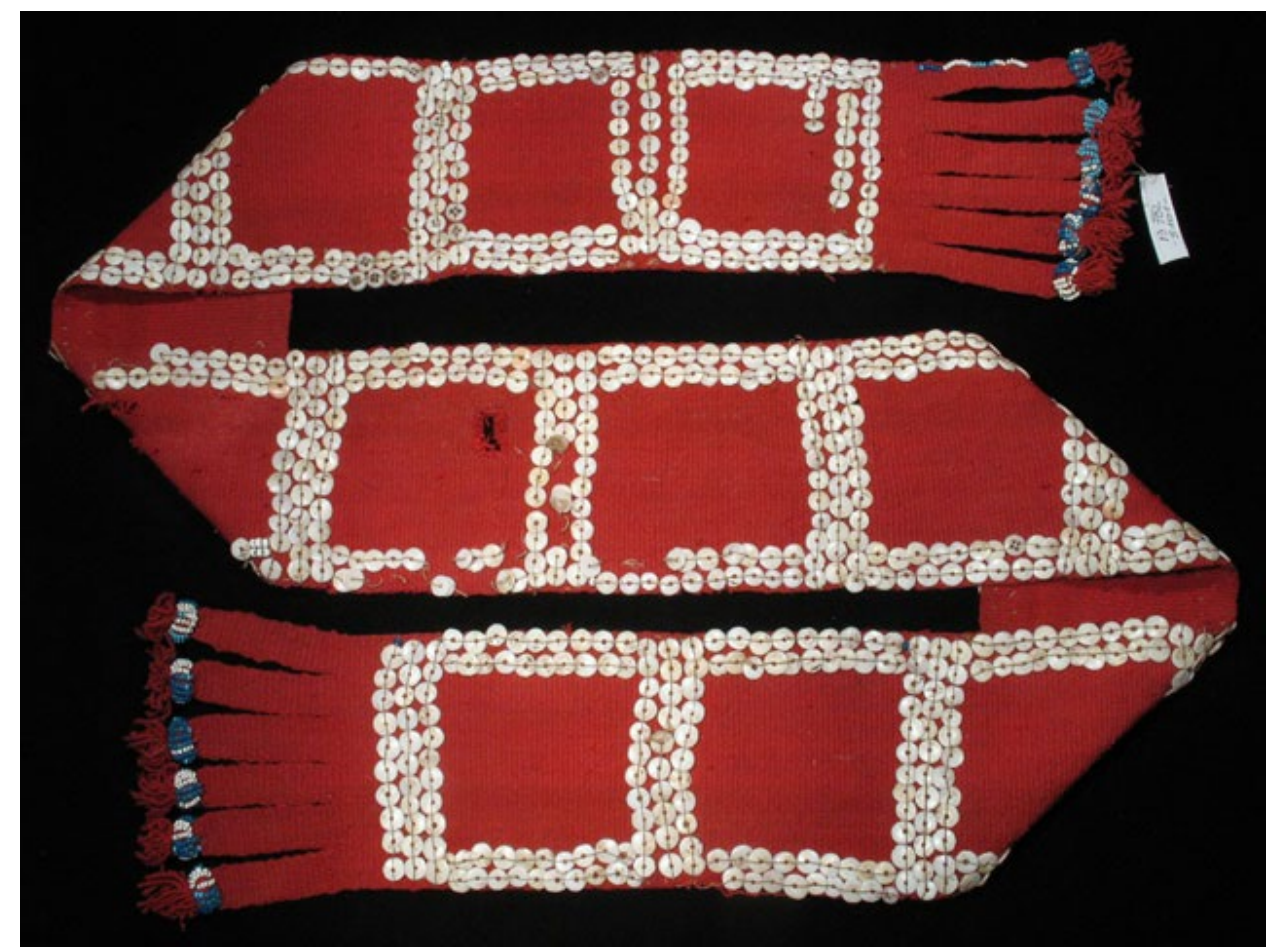

Figura 10. Banda cefálica con bordado de cuentas de valva, Pilagá, Chaco Argentino, 1912. Colección del Museo Etnográfico “J. B. Ambrosetti”.

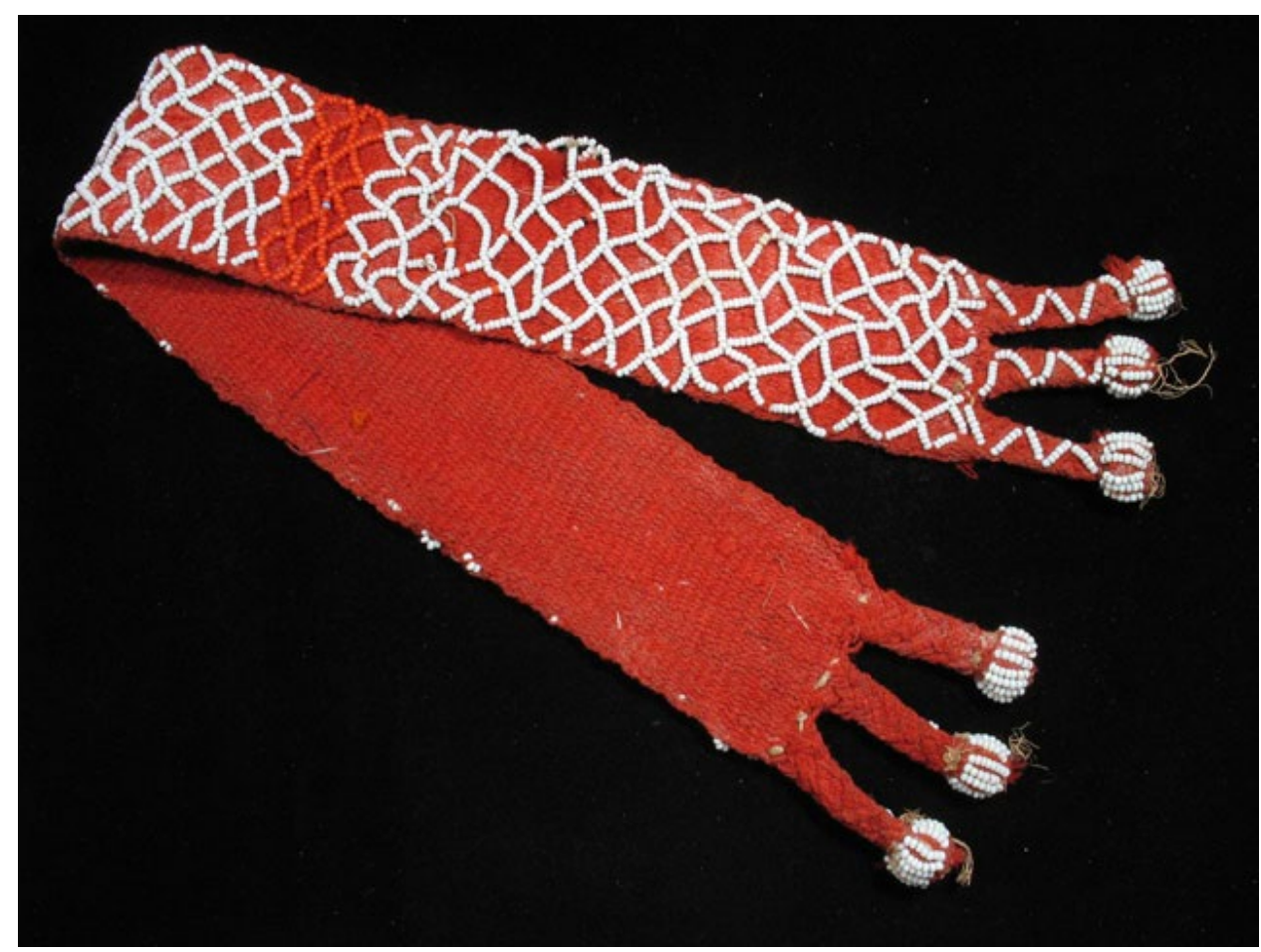

Figura 11. Banda cefálica con bordado chaquiras, Maká, 1939.

Colección del Museo Etnográfico “J. B. Ambrosetti”. 
objetos implicó la continuidad de saberes y conocimientos vinculados con la producción y el uso de los mismos. En los objetos analizados se registran dos aspectos visuales que los bordados de chaquiras tienen en común con los de valvas: la elaboración de diseños lineales y, como se menciona en el Catálogo del Museo del Barro, la constante presencia de la oposición blanco-rojo, "[...] rasgo característico de la etiqueta ceremonial de los grupos llaneros del Chaco [115]" (AA.VV., 2008) (Figuras 10 y 11). En la mayoría de los objetos bordados con chaquiras analizados, se registra el empleo selectivo de abalorios blancos, continuando con un aspecto de las cuentas de valva. Su uso no cambia el soporte sobre el que se aplican, éste sigue siendo de lana roja y con las mismas características estructurales textiles. Finalmente, se emplean en los mismos contextos que los bordados de valva, acompańados por elementos significativos como las plumas, constituyendo e integrando conjuntos simbólicamente relevantes para la producción de significaciones que hacen a las construcciones de los roles de quienes portan estos objetos (shamanes, guerreros, hombres en las danzas ceremoniales).

Aunque la incorporación de chaquiras en los bordados implicó la creación de nuevas técnicas y el uso de un material proveniente de las sociedades colonial y nacional, se mantuvo la elaboración de objetos ya conocidos y relevantes en las prácticas sociales de los distintos grupos étnicos. Así, las nuevas técnicas y materiales parecen haber sido usados para la reafirmación de ciertas pautas culturales, estéticas e identitarias.

\section{Diseños y colores: nuevos soportes para imá- genes conocidas}

Junto con las técnicas y los formatos, los diseños presentes en los objetos elaborados con cuentas de vidrio participan de los procesos de significación en los que dichos objetos intervienen. Las técnicas asociadas a las cuentas de vidrio y los diseños elaborados con ellas están íntimamente ligados, no son aspectos separados al momento de producción y uso de los objetos.
Ticio Escobar (1993) señala que la utilización de mostacillas dio la posibilidad de desarrollar un nuevo registro ornamental sobre la base de los diseños tribales [179]. En el Catálogo del Museo del Barro se propone que la introducción de mostacillas produjo la emergencia de un nuevo paradigma estético profundamente involucrado con el imaginario visual chaqueño (AA.VV., 2008).

El estudio detallado de los diseños y colores que se registran en distintos tipos de objetos tejidos o bordados con chaquiras de las primeras décadas del siglo XX, nos permitió ver que los mismos no son exclusivos de esta materialidad, sino que se observan también en otras producciones textiles de larga data como los tejidos de malla de caraguatá. Es decir, la incorporación de este nuevo material no implicó una pérdida, sino la multiplicación de los soportes en los que circulaban ciertas imágenes, que como veremos, parecen ser relevantes para los grupos étnicos del Gran Chaco y un acrecentamiento, por lo tanto, de los espacios de comunicación y construcción de distintos significados, entre ellos los identitarios.

Esto se evidencia especialmente en las gargantillas, pendientes pectorales, pendientes auriculares, brazaletes, anillos y pequeñas bolsas realizados con tejido "de" chaquiras que, como se desarrolló en un apartado anterior, parecen haber sido objetos nuevos consecuencia de la incorporación de este tipo de cuentas. Se registran en ellos diseńos de rombos concéntricos (Figuras 1, 2, 7, 8), líneas en zigzag, bandas o líneas horizontales, triángulos, líneas quebradas en ángulos rectos y clepsidras. Dibujos estrechamente relacionados con los mencionados se observan, asimismo, en los tejidos de malla de caraguatá (bolsos, "camisas de guerra") y en tejidos de lana elaborados en telar (fajas, ponchos). Diseños de hexágonos, octógonos y rombos aparecen en distintos formatos de bolsos de diferentes grupos elaborados en tejido de malla (Figura 12), así como en fajas (Figura 13) y ponchos tejidos en telar. Las bandas horizontales se registran en pequeñas bolsas y en las "camisas de guerra" en tejido de malla. Líneas quebradas en ángulos rectos en tejidos de malla de caraguatá y en tejidos de lana elaborados en telar. En cuanto a las clepsidras, solo se registran en objetos elaborados con lana y no en tejidos de malla de 


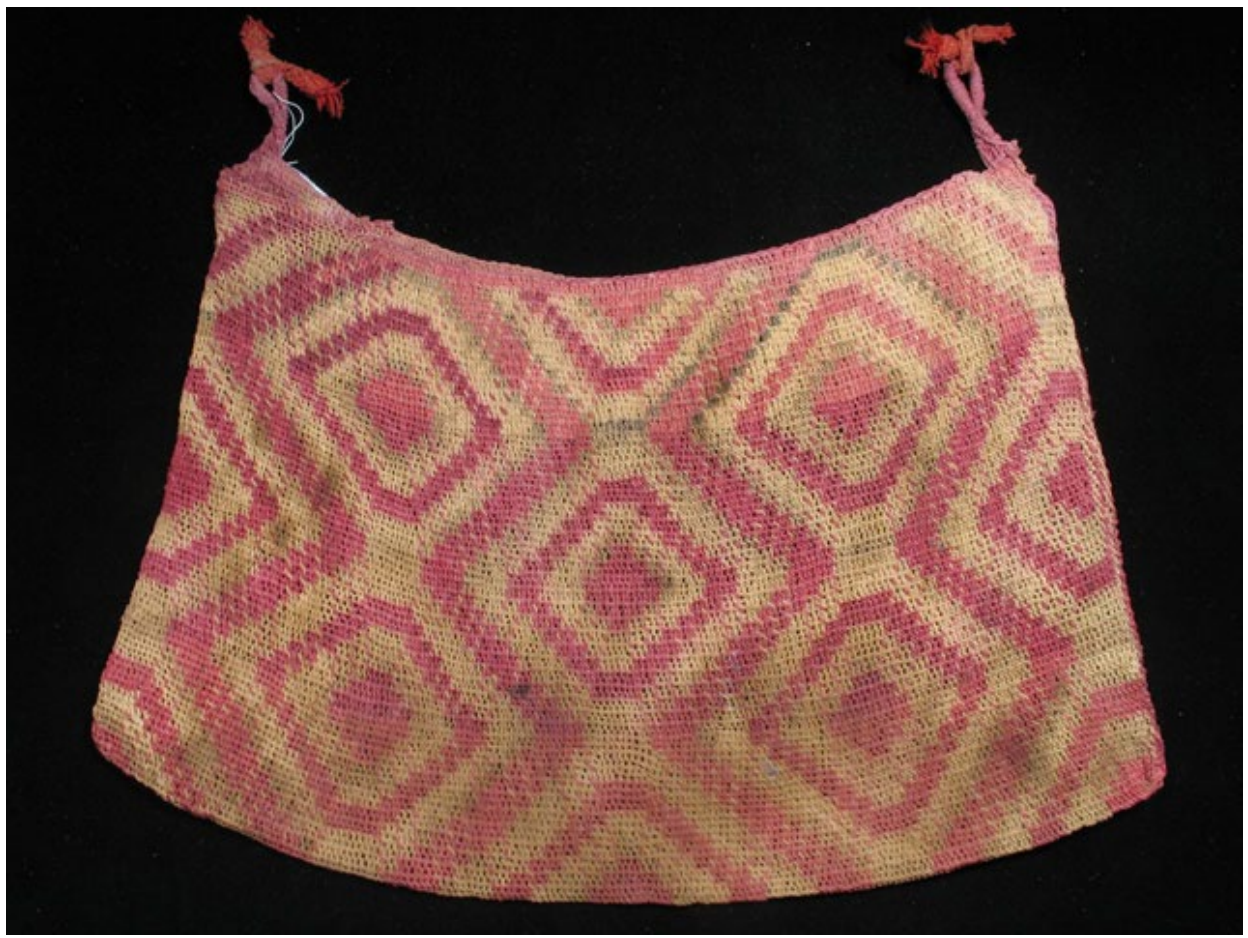

Figura 12. Bolsa de caraguatá en tejido de malla con diseño de rombos, Nivaclé, 1938. Colección del Museo Etnográfico "J. B. Ambrosetti”.

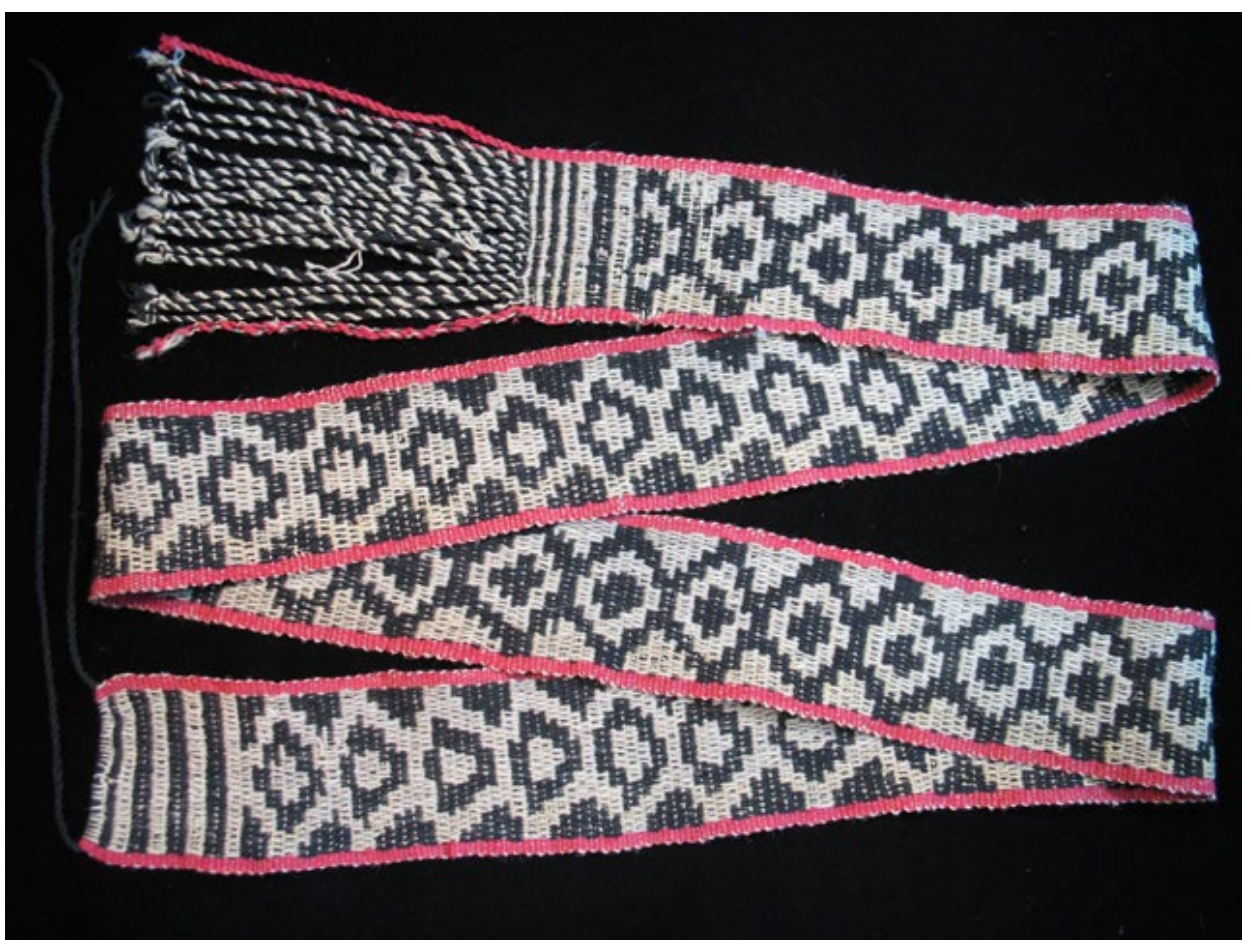

Figura 13. Faja de lana en telar con diseños de rombos, Pilagá, 1939. Colección del Museo Etnográfico “J. B. Ambrosetti”. 
caraguatá; Braunstein (1982) señala que la clepsidra es un motivo "típico" de distintos grupos qom, mocoví y pilagá, y que, probablemente, fue introducido en el Chaco por estos pueblos guaycurúes que, a fines del siglo XVII, retrocedieron hacia el este desde los bordes cordilleranos [482].

Es interesante señalar el predominio, en los tejidos "de" chaquiras "tipo red", de las configuraciones de diseños integradas por rombos, lo que también se observa en aquellos objetos cuya estructura textil es un tejido "tipo trenzado" $3 / 3$ o 5/5 que resulta en una retícula romboidal (Figura 3). Este predominio, asimismo, se observa en los tejidos de malla de caraguatá y en los tejidos de lana elaborados en telar. Aunque no podemos sacar conclusiones precisas, resulta interesante hacer esta observación ya que podría pensarse que, como desarrollaremos al final de este apartado, son dibujos simbólicamente relevantes entre los distintos pueblos y que juegan un rol importante en la construcción de las identidades a lo largo de sus historias.

Otro aspecto importante de los tejidos elaborados con mostacillas es el uso casi exclusivo, en todos los ejemplos atribuidos a los diferentes grupos étnicos de las colecciones de principios del siglo XX, de mostacillas rojas, azules y blancas. Susnik (1998) señala que las anchas gargantillas eran realizadas con cuentas de vidrio blancas, rojas y azules entre los grupos nivaclé, maká y toba [123]. Esta observación puede extenderse a otros objetos ya mencionados (pectorales, brazaletes, aros, etcétera) y a los grupos pilagá, toba-pilagá, toba oriental (qom) y lengua. El empleo de esta trilogía de colores es un elemento común entre algunos grupos del sur del Chaco paraguayo y del Chaco argentino y se registra también en tejidos de malla de caraguatá y tejidos de lana maká, nivaclé, pilagá, toba y lengua (Elías, 2012). ${ }^{19}$

Se observa, entonces, una relación de continuidad entre los diseńos y colores de los objetos elaborados con chaquiras y aquellos de los tejidos de malla de caraguatá y los tejidos de lana. En este sentido, se

19 Respecto a las bolsas de caraguatá maká y nivaclé, otros autores señalaron el uso predominante de los colores rojo y azul (Braunstein, 1982; Escobar, 1993; GómezPerasso, 1977). puede plantear que el uso de este tipo de cuentas contribuyó a la producción y circulación de imágenes persistentes y relevantes entre los grupos étnicos del Gran Chaco.

Siguiendo estos razonamientos, es interesante referir al texto del misionero jesuita Florián Paucke (1943), quien en el siglo XVIII actuó en la misión de San Javier entre grupos mocoví. En su libro se puede observar un dibujo realizado por él (lámina XV), en el que aparecen representadas dos mujeres tatuadas. Una parte del tatuaje consiste en una banda ancha que se extiende entre un hombro y otro, en la que se observan diseños romboidales y triángulos. Sin dejar de considerar el filtro que implica la mirada de Florián Paucke y la transposición al dibujo, es interesante señalar la similitud en el formato con las anchas gargantillas de chaquiras (objetos novedosos en la cultura material de los pueblos) y la presencia de motivos de rombos, predominantes en los tejidos "de" chaquiras (Figuras 14 y 15). Sumado a esto, cabe resaltar que, al igual que los objetos de indumentaria y "adorno" corporal elaborados con chaquiras estudiados aquí, los tatuajes constituyen elementos de significación de los cuerpos que, dialécticamente con ellos, contribuyen a la construcción de la identidad de quien los porta.

Estos elementos en común entre el dibujo y los comentarios de Florián Paucke y los objetos con chaquiras, en cuanto a los diseños y sus relaciones con los cuerpos de quienes los portan, no parecen ser casuales, más bien parecen evidenciar los complejos procesos de cambio y continuidad que ha implicado la incorporación de las cuentas de vidrio entre los grupos indígenas del Gran Chaco. Los actores indígenas, a través de distintas prácticas sociales vinculadas con la producción y el uso de dichos objetos, se apropiaron, negociaron y resignificaron ese material foráneo, haciéndose partícipes activos de la construcción de sus propias identidades y cultura en el marco de conflictivas relaciones interculturales con las sociedades coloniales y nacionales de las que procedía dicho material. 


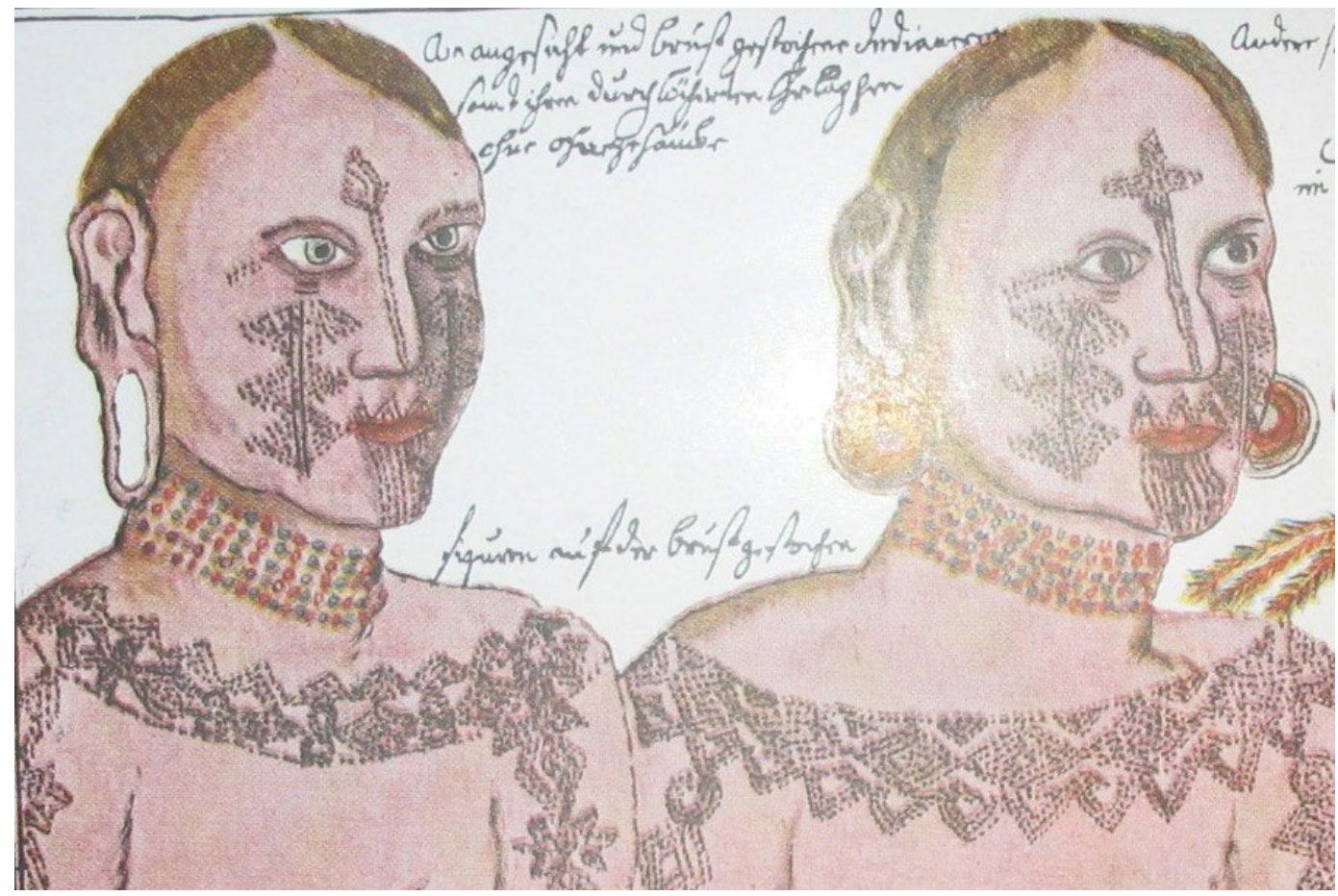

Figura 14. Detalle de la lámina XV del misionero jesuita Florian Paucke (Paucke, 1943). Mujeres Mocoví con tatuajes en forma de bandas con diseños de rombos y triángulos.

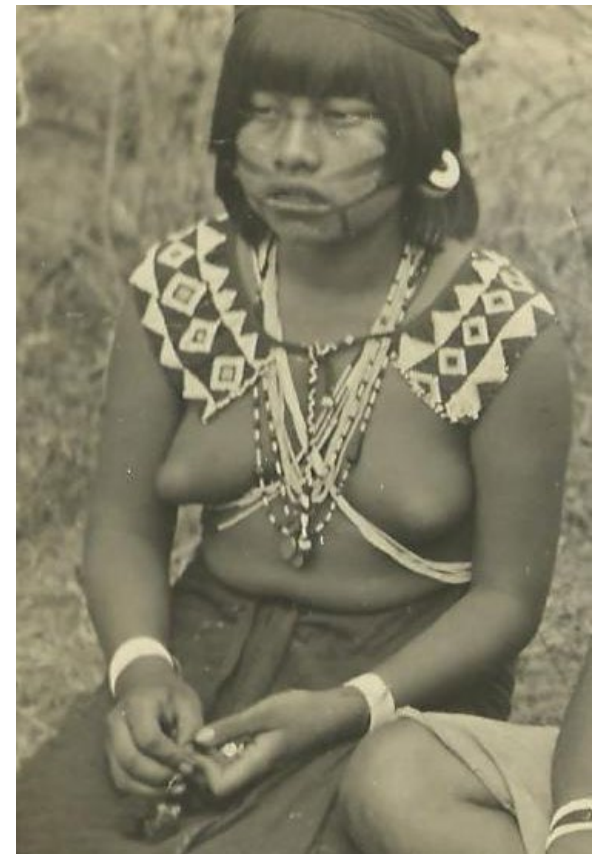

Figura 15. Detalle de fotografía de mujeres Maká, Jardín Botánico, Asunción, 1935. Llevan la ancha gargantilla en tejido "tipo red" con diseños de rombos y triángulos. Colección del Museo Etnográfico "Dr. Andrés Barbero".

\section{Las chaquiras en la construcción de la identidad de los maká del Chaco paraguayo}

Actualmente los maká siguen produciendo y usando los distintos tipos de objetos elaborados con chaquiras que hemos descrito. En el ańo 2013 se realizaron entrevistas a personas del pueblo maká que viven en la Nueva Colonia Indígena Maká, en Mariano Roque Alonso (Paraguay). En este apartado nos concentraremos en las entrevistas realizadas a los ancianos María Gómez (mujer nivaclé que vive hace muchos años con los maká) y Félix Zorrilla. En las mismas hablamos sobre el empleo de chaquiras entre los maká, orientándose la conversación hacia la tercera década del siglo XX. ${ }^{20}$ Durante esta

20 En el año 2013, he llevado a cabo un breve trabajo de campo en la comunidad Maká que vive en la Nueva Colonia Indígena Maká, en las afueras de la ciudad de Asunción (Mariano Roque Alonso, Paraguay). El trabajo se extendió durante una semana, en la que entrevisté a tres personas. Las entrevistas versaron sobre el empleo de mostacillas durante la tercera década del siglo XX y en la actualidad, y fueron realizadas a María Gómez (anciana nivaklé que sigue realizando tejidos de mostacillas y que hace muchos años vive en la colonia), Félix 
década, se produjo la Guerra del Chaco entre Paraguay y Bolivia (1932-1935) por el dominio del Chaco Boreal. Los maká fueron uno de los grupos indígenas que se vieron afectados por este conflicto; originarios del Chaco, el general Juan Belaieff, quien trabajaba para el Estado paraguayo, los empleó como baqueanos en los trabajos de relevamiento topográfico y estratégico de esa zona del Chaco. $\mathrm{Al}$ terminar la guerra, Belaieff trasladó a un grupo de ellos a la ciudad de Asunción, siendo muy importante la comunidad maká que actualmente vive cerca de esta ciudad (Giordano, 2004).

Lo mencionado por los dos ancianos en sendas entrevistas evidencia los procesos de apropiación y negociación implicados en la producción y el uso de las mostacillas, en estrecha relación con la construcción de su identidad en marcos históricos concretos como son la Guerra del Chaco y la situación actual de los maká en la sociedad nacional paraguaya.

Interesa, primero, concentrarse en lo que los ancianos contaron respecto a la obtención de las mostacillas. En sus comentarios puede observarse claramente que éstas no eran objetos que se conseguían en el monte chaqueño, sino en la ciudad de Asunción o habían sido traídos por el contacto con los "blancos”. María Gómez señala que entre los antepasados (hacia el año 1935) había una señora, ya fallecida, a la que le daban las mostacillas: "[...] le da un señor que se llamaba general Juan Belaieff [...]. Ahí empezó a hacer collares, [...] que usan en los bailes, cinturón [...] pulsera, o los aros”. Cuenta que, estando en el Chaco, iban a buscar las mostacillas a Asunción y su padre llevaba al Chaco la mostacilla que conseguía en esa ciudad. En el relato de María Gómez, la mostacilla aparece estrechamente

Zorrilla (anciano maká que transitó su niñez y juventud durante la Guerra del Chaco en los años treinta del siglo $\mathrm{XX)}$ y Emilio Torres, quien fue el encargado de guiarme por la comunidad, establecer a quiénes entrevistar y realizar la traducción de lo que contaban los ancianos, ya que hablaban en idioma maká. Por esto, las transcripciones de las entrevistas de María Gómez y Félix Zorrilla están en tercera persona.

Las entrevistas se realizaron con el apoyo de imágenes impresas, en tamańo natural y a color, de los objetos maká con cuentas de vidrio de las colecciones estudiadas e imágenes de archivo con personas maká usando distintos "adornos" elaborados con mostacillas, las cuales fueron mostradas a los entrevistados. relacionada con la figura del general Juan Belaieff y la guerra:

Esa época... bueno... yo creo que es 1932 o $34 .$. esa época, la guerra, entonces cuando termina esa guerra, entonces al general ruso le quieren mucho los pueblos maká. Esa guerra cuando termina él mismo nos trajo acá, a Asunción; tenemos una isla que... hay como 335 hectáreas que él consiguió. Después él mismo consiguió la mostacilla, el general ruso, que llevan los pueblos maká; ahi empezó a trabajar cada familia, hacen bolso [...], pulseras o aros... con diferentes colores.

Otro lugar que señala María Gómez donde su padre conseguía mostacilla es Bolivia: "Esa época, había pobres acá en Paraguay, después su padre se fue donde están los bolivianos, ahí encontró mostacillas..., más fondo ahí, en la frontera, yo creo que es la frontera ahora, se fue su papá a Bolivia, y ahí él siempre trae mostacillas [...]". ${ }^{21}$

Félix Zorrilla señala que las mostacillas eran conseguidas en Asunción y llevadas al monte, además de que se obtenían del intercambio con otros grupos indígenas como los lengua y "chulupí" (nivaclé). Traduce Emilio Torres:

Esta es gente que en esa época viven en el Chaco. [...] ellos ya saben que hay acá en Paraguay la mostacilla, pero no habia mucho. La gente, uno, vienen acá en Asunción, buscan de esa clase, mostacilla, después consiguen, tienen que volver otra vez donde están, el Chaco, que vivian antes en el monte [...]. Este señor dijo que... las otras razas tenían también antes; [...] consiguieron de los otros, los que están en Bolivia... los Lenguas, ellos tenian también"; "las otras razas, [...], ellos tenian antes, los chulupi o lenguas, [...], en Bolivia, que [...] tienen mostacilla; porque esa época usaban como collar o cinto de caracol, caracol es lo que usaba esa época, porque lo usaban antes; después, cuando viene un señor acá a Asunción, ahi consigue la

21 Elías, M. A. (2013, 24 de octubre). Entrevista a María Gómez, traducción de Emilio Torres, Nueva Colonia Indígena Maká, Mariano Roque Alonso, Paraguay. 
mostacilla y la gente... quieren hacer, entonces hacen collares... las mostacillas..."; "[...] los hombres [conseguian las mostacillas]; cuando viven todavia en el monte, las casas tipicas ahi... si uno viene acá en Asunción, entonces consiguen esa clase [mostacillas]. Si uno habla en guarani... eso, no hay problema; porque esa época, es la guerra que hablan los paraguayos en guarani; algunos hablan en guarani, asi es más fácil, entonces vienen acá [Asunción] y buscan de mostacilla, llevan a otros, su gente decimos, parientes, [...] los maká. ${ }^{22}$

Los comentarios de Félix Zorrilla dan cuenta de que las mostacillas eran objetos que se conseguían, además que en Asunción, a través de otros grupos étnicos como los "chulupí" (nivaclé) y los lengua, quienes pareciera que tenían mostacillas antes que los maká, y en Bolivia. Esto deja en evidencia un antes y un después: antes se usaba el collar de cuentas de valva ("caracol") y, después, "cuando viene un señor a Asunción”, se consiguen mostacillas y la gente hace collares con ellas. Asimismo, evidencia la construcción de una identidad que diferencia claramente el monte donde vivían los maká, donde estaban las casas "típicas" y donde no se conseguían estas cuentas, y la ciudad de Asunción, donde sí se conseguían y donde había que hablar guaraní.

En ambas entrevistas, las mostacillas parecen intervenir en distintos momentos de la construcción de una identidad maká múltiple que se configura entre el monte (antes) y la ciudad de Asunción, entre los maká y los paraguayos, los maká y Bolivia, y los maká y nivaclé y lengua. Por otro lado, se evidencia el proceso de apropiación de esta materia prima y a los maká como sujetos activos, en tanto son ellos quienes buscan y consiguen estas cuentas y "quieren" hacer collares, bolsas, etcétera.

En la entrevista a Félix Zorrilla queda explicitado que las mostacillas y los objetos elaborados con ellas son elementos que intervienen en los procesos de diferenciación respecto a otros grupos étnicos. Señala que los "chulupíes" (nivaclé) usaban un solo color

22 Elías, M. A. (2013, 23 de octubre). Entrevista a Félix Zorrilla, traducción de Emilio Torres, Nueva Colonia Indígena Maká, Mariano Roque Alonso, Paraguay. de mostacillas. Al mostrarle unos pendientes auriculares que solo se registran en colecciones maká (ver Figura 1) y preguntarle si ese tipo de aros usaban los "chulupíes" (nivaclé) responde: "No, más fino lo que usaban, que no es tan ancho...". Señala, entonces, una foto de un collar maká elaborado con un tejido "tipo trenzado" de dos hilos de caraguatá que forma un tejido romboidal alargado (Figura 9), mencionando que "esa clase es la que hacen los chulupíes... hasta ahí nomás... no había muchos colores...” y que, en esa época, los maká usaban más colores de mostacillas. Félix Zorrilla nos indica que los aros que se observan en la Figura 1 solo los usaban los maká. ${ }^{23}$ El formato y los colores de los aros de mostacilla usados por los Maká intervenían, por lo tanto, en la construcción de la identidad maká y en los procesos de diferenciación respecto a otros grupos del Chaco, en este caso, los nivaclé.

En complejos contextos de interculturalidad, en un ir y venir entre el monte y la ciudad, entre los grupos maká, lengua y nivaclé, entre los maká y Paraguay y Bolivia (la guerra), entre los maká y los paraguayos, los objetos de mostacilla obtenida principalmente en Asunción participaron y participan en la resignificación, afirmación y elaboración de la identidad maká.

\section{Conclusiones}

$\mathrm{Al}$ inicio de este artículo, hemos citado una serie de trabajos que problematizan el pensar a las sociedades indígenas en situaciones coloniales como sujetos pasivos sin capacidad de accionar frente a condiciones hegemónicas, poniendo en cuestión la categoría de cambio e incorporación de elementos foráneos como pérdida de la "pureza original" de dichas sociedades. Por el contrario, los autores citados proponen dar cuenta de la agencia de los indígenas frente a las instancias hegemónicas y estructuras sociales, pensándolos como sujetos activos que en cada práctica social se apropian, negocian, crean, recrean y reinterpretan dichos elementos a partir de lo local y de su presente. Es en estas prácticas sociales donde se construyen históricamente las identidades étnicas.

23 Elías, M. A. (2013, 23 de octubre). Entrevista a Félix Zorrilla, traducción de Emilio Torres, Nueva Colonia Indígena Maká, Mariano Roque Alonso, Paraguay. 
Consideramos que el ingreso de las mostacillas, cuentas de vidrio, chaquiras o abalorios a la región del Gran Chaco y su empleo por parte de los distintos grupos étnicos es un claro ejemplo de la capacidad de agencia de los indígenas. Estas cuentas procedentes de las sociedades coloniales y nacionales, no producidas por las poblaciones locales, fueron apropiadas y resignificadas por ellas a partir de concepciones y proyectos propios.

El estudio de las estructuras textiles, formatos y diseños de los objetos elaborados con mostacillas son testimonio de la puesta en práctica de saberes y conocimientos locales de larga data entre los distintos grupos étnicos del Gran Chaco, como los vinculados con la manufactura y el uso de collares y bordados con cuentas de valva blanca. Una situación similar se observa en aquellos objetos con tejidos "de" chaquiras que, aunque con formatos novedosos, sirvieron como soportes de imágenes antiguas y relevantes entre estas sociedades; los tatuajes de las mujeres mocoví dibujados por Florián Paucke en el siglo XVIII nos dan una pauta de esto.

Por lo tanto, la incorporación de esta materia prima, producto de la relación con los "blancos", no parece haber implicado una pérdida o disrupción en las culturas e identidades de las sociedades indígenas consideradas; por el contrario, parece haber contribuido a la afirmación de ellas a partir de complejos procesos de apropiación y negociación en las prácticas sociales de producción y uso de sus integrantes.

Lo anterior, también, puede plantearse para los maká de Paraguay, entre los que el uso de mostacillas para elaborar objetos de indumentaria y "adorno" corporal implica e implicó, más que la puesta en riesgo de su identidad, la construcción histórica y reafirmación de la misma frente a las sociedades "no indígenas". Como se deduce de lo mencionado por los dos ancianos entrevistados, estos objetos han intervenido, a través de sus formas y colores, y más ampliamente, a través de su materialidad "foránea", en sus procesos de construcción identitaria.

Para finalizar, nos interesa citar a la antropóloga Marina Matarrese (2012), quien menciona cómo las mujeres pilagá conciben la incorporación de nuevos objetos y diseńos y cómo éstos se relacionan con su condición étnica, lo cual interpela nuestra forma de pensar las producciones indígenas con cuentas de vidrio que venimos analizando:

\section{[...] para las artesanas la incorporación de} nuevos objetos y diseños no significa una pérdida o disrupción de la condición étnica asociada a la nueva producción material, y lejos de testimoniar un debate entre tradición y modernidad [...] alecciona acerca del modo en que los aborigenes piensan, recrean y resituan su nueva situación de interculturalidad [106].

\section{Referencias citadas}

AA.VV. (2008). Catálogo Museo de Arte Indigena. Asunción: Centro de Artes Visuales/ Museo del Barro.

Arenas, P. (1997). Las bromeliáceas textiles utilizadas por los indígenas del Gran Chaco. Parodiana, 10(1-2), 113139. Buenos Aires: CEFYBO, CONICET.

Beck, H. (1994). Relaciones entre blancos e indios en los territorios nacionales de Chaco y Formosa 1885-1950. Cuadernos de Geohistoria Regional, 29, 206 pp. IIGHI, Resistencia, Argentina.

Berlo, J. C. (1996). Beyond Bricolage: Women and Aesthetic Strategies in Latin American Textiles". En Schevill, M., Berlo, J. C. y Dwyer, E. B. (Eds.). Textiles Traditions of Mesoamerica and the Andes (pp. 437-479). Texas: University of Texas Press.

Bilbao, S. (2002). Alfred Métraux en la Argentina. Infortunios de un antropólogo afortunado. Caracas: Comala.

Boccara, G. (2005, 14 de febrero). Antropología diacrónica. Dinámicas culturales, procesos históricos y poder político. Nuevo Mundo Mundos Nuevos. Recuperado de https://nuevomundo.revues.org/589

Boggiani, G. (1900). Compendio de etnografía paraguaya moderna. Revista del Instituto Paraguayo III(28), Asunción.

Braunstein, J. (1982). El problema de la significación de la cultura material de los indios Maká. Tesis doctoral, FFyL, Universidad de Buenos Aires, Buenos Aires. 
Braunstein, J. y Miller, E. (1999). Ethnohistorical Introduction. En Miller, E. (Ed.). Peoples of the Gran Chaco (pp. 1-22). Wesport: Bergin \& Garvey.

Chase-Sardi, M. (2003). ¡Palavai nuu! Etnografía Nivaclé. Biblioteca Paraguaya de Antropología, 45(I- II). Paraguay: CEADUC.

Elías, M. A. (2011). Tejidos y bordados indígenas de chaquiras de la región del Gran Chaco Sudamericano. En 25a Reunión Anual del Comité Nacional de Conservación Textil de Chile, Santiago de Chile.

Elías, M. A. (2012). Textiles indígenas del Gran Chaco Sudamericano. En Elías, M. A. y Mencia, A. Textiles del Chaco. Catálogo del MEAB (pp. 28-97). Asunción: Museo Etnográfico “Dr. Andrés Barbero”.

Elías, M. A. y Mencia, A. (2012). Textiles del Chaco. Catálogo del MEAB. Asunción: Museo Etnográfico “Dr. Andrés Barbero".

Escobar, T. (1993). La belleza de los otros. Arte indigena del Paraguay. Asunción: Centro de Artes Visuales/ Museo del Barro.

Escobar, T. (2007). Una interpretación de las artes visuales en el Paraguay. Asunción: ServiLibro.

Femenías, B. (1998). "Ethnic artists and the appropriation of fashion: embroidery and identity in Caylloma, Perú. Chungara, 30(2), 197-206.

Giordano, M. (2004). De Boggiani a Métraux. Ciencia antropológica y fotografía en el Gran Chaco. Revista Chilena de Antropología Visual, 4, 365-390. Santiago de Chile, Chile.

Gómez-Perasso, J. (1977). Estudios mak'a, cultura material. Etnografía Paraguaya, 1, Asunción.

Guerrero, F. M. (1913, 2 de octubre). [Carta a Juan Bautista Ambrosetti]. Carpeta 018 GUERRERO, Archivo Fotográfico y Documental del Museo Etnográfico "J. B. Ambrosetti”.

Iriarte, I. (2002). "Adornos con chaquiras. Un arte de mujeres”. En Pereda E. Hijos del viento. Arte de los pueblos del sur siglo XIX. Buenos Aires: Fundación PROA.
Lagrou, E. (2013). Chaquira, el inka y los blancos: las cuentas de vidrio en los mitos y en el ritual kaxinawa y amerindio. Revista Española de Antropología Americana, 43(1), 245-265. Madrid, España.

Matarrese, M. (2012). Dimensiones estéticas de la política artesanal en Formosa: el caso de los pilagá. Claroscuro. Revista del Centro de Estudios sobre Diversidad Cultural, 11. Recuperado de http://ppct.caicyt.gov.ar/index.php/ claroscuro/article/view/2336.

Mendoza, M. (1981). Análisis morfológico-comparativo de ergología Toba. Tesis de grado en Ciencias Antropológicas, FFyL, Universidad de Buenos Aires, Argentina.

Mendoza, M. (1983). La ergología de una banda toba en el recuerdo de Pascual Buija. Serie de Monografías (Antropología). Lomas de Zamora, Argentina.

Mendoza, M. (1999). The Western Toba: Family Life and Subsistence of a Former Hunter-Gatherer Society. En Miller, E. (Ed.). Peoples of the Gran Chaco (pp. 81-108). Wesport: Bergin \& Garvey.

Métraux, A. (1933). Nouvelles de la Mission A. Métraux. Journal de la Société des Américanistes, XXV, 203- 205. París: Sociedad de Americanistas.

Métraux, A. (1946). Ethnography of the Chaco. En Steward, J. (Ed.). Handbook of South American Indians (pp. 197-370). Washington D. C.

Millán de Palavecino, M. D. (1973). Tejidos Chaqueños. Relaciones (Nueva Serie), (VII), 65-83. Argentina: Sociedad Argentina de Antropología.

Níklison, J. E. (1916). Investigación en los Territorios Federales del Chaco y Formosa. Boletín del Departamento Nacional del Trabajo, 34-II, libros III y IV, Buenos Aires

Nordenskiöld, E. (1929). Analyse ethno-géographique de la culture matérielle de deux tribus indiennes du Gran Chaco. Études d'Ethnographie comparée, I. París: Genet.

Ortner, S. (2016). Antropología y teoría social. Cultura, poder y agencia. Buenos Aires: UNSAM Edita.

Palavecino, E. (1933). Los indios pilagá del río Pilcomayo. Anales del Museo Nacional de Historia Natural Bernardino Rivadavia, XXXVII (pp. 517-582). Buenos Aires: Museo Nacional de Historia Natural Bernardino Rivadavia. 
Palavecino, E. (1935). Breve noticia sobre un viaje etnográfico al Chaco central. Revista Geográfica Americana, II(23), 77-84.

Paucke, F. (1943). Hacia allá y para acá (Una estada entre los indios mocobies, 1749-1767). Publicaciones especiales del Instituto de Antropología, Departamento de Investigaciones Regionales, V. Tucumán, Argentina: Universidad Nacional de Tucumán.

Saguier, E. (s.f.). Genealogía de la tragedia argentina. La violenta transición de un orden patrimonial-predatorio a una democracia crecientemente condicionada por el pretorianismo (1870-1912). Recuperado de http://www. er-saguier.org/obras/udhielal/pdfs/Tomo_15/Tomo-XVApendices.pdf

Seiler-Baldinger, A. (1994). Textiles. A classification of techniques. Washington D.C.: Smithsonian Institution Press.

Suárez, G. (2010). Tejidos de cuentas. Diferentes estructuras: una clasificación y ordenamiento. Argentina.
Susnik, B. (1998). Artesanía indigena. Asunción, Paraguay: El Lector.

Vogt, J. (1933). "La tribu Maccá. Apuntes de viaje". Notas del Museo de Historia Natural del Jardín Botánico, 3, pp. 121-128. Asunción, Paraguay.

Wright, P. (2005). Los indígenas del Chaco argentino. En AA.VV. Aborigenes del Gran Chaco. Fotografias de Grete Stern 1958-1964 (pp. 25-33). Buenos Aires: Fundación Antorchas, Fundación CEPPA.

Yturbide T. y Mozzi, C. (1998). La chaquira en México. México: Museo Franz Mayer- Artes de México. 